Article

\title{
Biomass Burning and Gas Flares create the extreme West Afri- can Aerosol Plume Which Perturbs the Hadley Circulation and thereby Changes Europe's Winter Climate
}

\author{
Keith Potts ${ }^{1}$
}

\author{
1 Kyna Keju Pty Ltd; Keith.Potts@bigpond.com \\ * Correspondence: Keith.Potts@bigpond.com
}

\begin{abstract}
Three significant changes have occurred in the winter climate in Europe recently: increased UK flooding; Iberian drought; and warmer temperatures north of the Alps. The literature links all three to a persistent, significant increase in sea level pressure over Southern Europe, the Mediterranean, Iberia and the Eastern Atlantic (SEMIEA) which changes the atmospheric circulation system: forcing cold fronts to the north away from Iberia; and creating a south westerly flow around the northern perimeter of the high-pressure region bringing warmer, moist air from the subtropical Atlantic to the UK and Europe which increases precipitation in the UK and raises the temperature in Europe. I use the Last Millennium Ensemble, MERRA-2 and Terra-NCEP data to demonstrate that the extreme, anthropogenic, West African aerosol Plume (WAP) which only exists from December to April perturbs the northern, regional Hadley Circulation creating the high pressure in the SEMIEA. I also show that the anthropogenic WAP has only existed in its extreme form in recent decades as the two major sources of the WAP aerosols: biomass burning; and gas flaring have both increased significantly since 1950 due to: a four-fold increase in population; and gas flaring rising from zero to 7.4 billion $\mathrm{m}^{3} /$ annum and note that this time span coincides with the changes in the three elements of the winter climate of Europe. I also suggest that it may be possible to eliminate the WAP and return the winter climate of Europe to its natural state after the crucial first step of recognising the cause of the changes is taken.
\end{abstract}

Keywords: Biomass burning; Anthropogenic aerosols; West Africa; United Kingdom Floods; Iberian Drought; European winter temperatures; Last Millennium Ensemble; NASA MERRA-2;

\section{Introduction}

\subsection{Hypothesis}

This paper explores the hypothesis that the West African aerosol Plume (WAP), one of the eight continental scale aerosol plumes which now exist each year (Appendix A), perturbs the regional, northern Hadley circulation in winter creating anomalous high pressure over Southern Europe, the Mediterranean Sea, Iberia and the Eastern Atlantic (SEMIEA) which creates floods in the UK, drought in Iberia and warmer temperatures north of the Alps. The sequence of stages required to create these changes is:

1. The extreme WAP forms in December during the dry season in West Africa and clears in April at the start of the West African monsoon;

2. The WAP absorbs solar radiation heating the atmosphere; which

3. Reduces solar radiation at the surface and cools the surface;

4. The warmer atmosphere and cooler surface create a temperature inversion which reduces convection in the region of the plume; 
5. The cooler surface under the plume and unchanged surface temperature and solar radiation to the north of the plume forces the convection column of the northern regional Hadley Circulation north; this

6. Forces the entire regional Hadley Circulation to the north; which

7. Moves the regional sub-tropical high-pressure ridge north from its natural position and creates the persistent high-pressure region over SEMIEA; which

8. Forces cold fronts to the north creating drought in Iberia; and

9. Advects warm, moist air from the central Atlantic Ocean into northern Europe and the UK; which

10. Creates floods in the UK; and

11. Raises the winter temperature north of the Alps.

To demonstrate these connections I use the Aerosol Optical Depth (AOD) of the WAP which [1] and [2] confirm to be an acceptable measure for the analysis of aerosols. AOD from three datasets: the Last Millennium Ensemble (LME) modelling [3]; MERRA-2 Reanalysis (M2) which assimilates aerosol data [4]; and MODIS on the NASA Terra satellite [2] is used. The LME and M2 AOD data is analysed with data extracted from the same dataset whilst the Terra data is used with data from the NCEP Reanalysis [5] (together $\mathrm{TN}$ ). The derivation of the Terra AOD data is described in [6] and the uncertainty in the AOD measured by the NASA Terra and Aqua satellites is " $\triangle \tau= \pm 0.05 \pm 0.15 \tau$ over land" and AOD retrievals can be used in monitoring the aerosol radiative forcing of the global climate [1]. The error in the annual AOD measurements by these satellites when compared with AERONET is less than 2\% [2].

\section{1,2 Areas Used}

The areas used are listed below with descriptors and shown in Figure 1:

1. AOD (WAP Area):

2. Surface Temperature West Africa:

3. Omega West Africa:

4. Pressure (SEMIEA):

5. Rainfall Southern Europe (MIEA):

6. Rainfall Northern Europe (UK):

7. Temperature Northern Europe: $0^{\circ} 10^{\circ} \mathrm{N}$ and $0^{\circ} 10^{\circ} \mathrm{E}$

$6^{\circ} 12^{\circ} \mathrm{N}$ and $5^{\circ} \mathrm{W} 5^{\circ} \mathrm{E}$

$10^{\circ} 15^{\circ} \mathrm{N}$ and $0^{\circ} 10 \mathrm{E}^{\circ}$

$30^{\circ} 45^{\circ} \mathrm{N}$ and $30^{\circ} \mathrm{W} 15^{\circ} \mathrm{E}$

$35^{\circ} 43^{\circ} \mathrm{N}$ and $20^{\circ} \mathrm{W} 10^{\circ} \mathrm{E}$

$50^{\circ} 60^{\circ} \mathrm{N}$ and $10^{\circ} \mathrm{W} 10^{\circ} \mathrm{E}$

$45^{\circ} 60^{\circ} \mathrm{N}$ and $15^{\circ} \mathrm{W} 30^{\circ} \mathrm{E}$ 


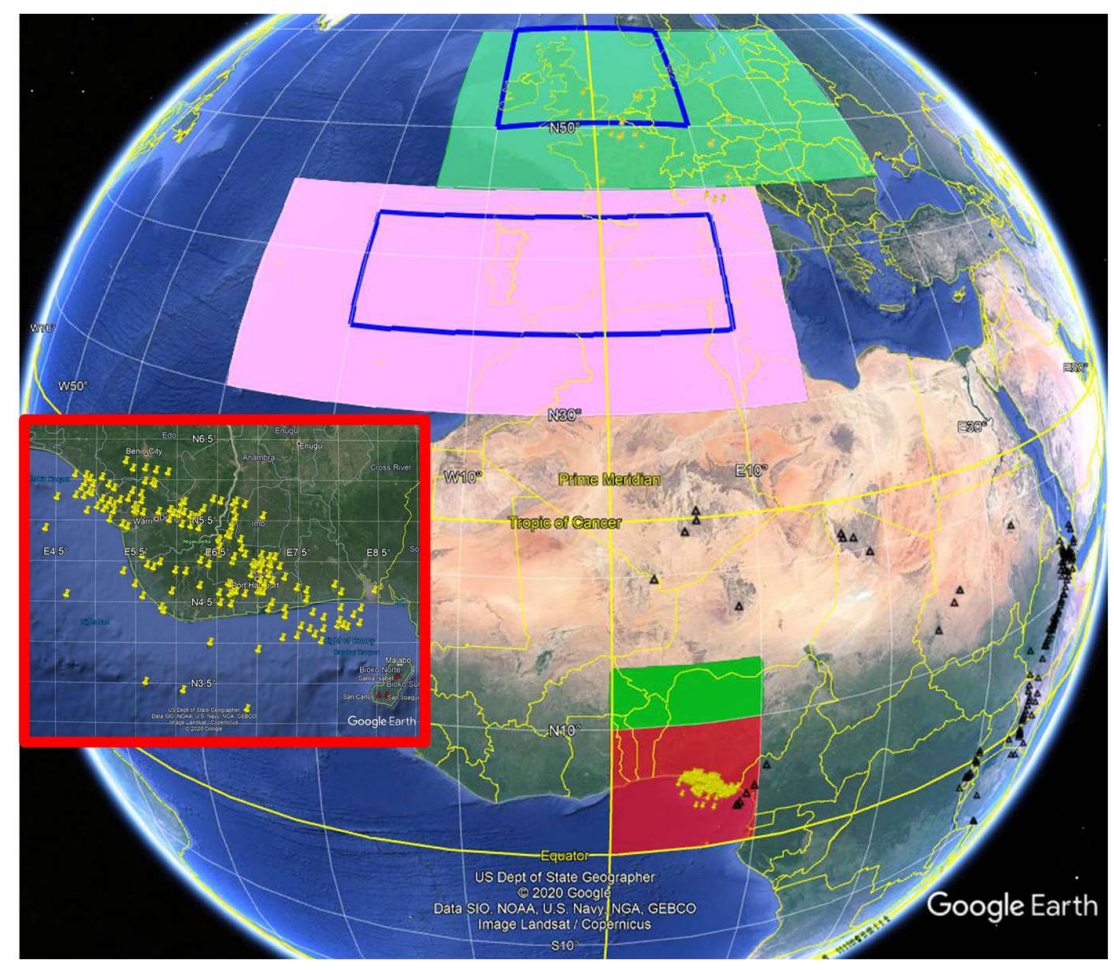

Figure 1: Google Earth image showing: the areas used; the locations of Nigerian gas flares (National Oceanic and Atmospheric Administration (NOAA) and the Global Gas Flaring Reduction Partnership (GGFRP)) in yellow; and African volcanoes (Global Volcanism Program (GVP)) in black. Inset southern Nigerian gas flares. Map data: Google Earth, US Dept of State Geographer, SIO, NOAA, U.S. Navy NGA, GEBCO; image Landsat/Copernicus. @ Google Maps 2021.

\subsection{The Anthropogenic West African Aerosol Plume}

The major anthropogenic aerosol plume located in the region most likely to affect the European regional Hadley Circulation in winter occurs over West Africa - the WAP. It is one of eight continental scale aerosol plumes (Appendix A) which occur annually and can be identified on the monthly mean 0.55 micron AOD data from the NASA Terra satellite distributed on the NASA Giovanni System.

The monthly average AOD of the WAP Area from the Terra satellite and the annual AOD cycle are shown in Figure 2 to demonstrate the peak anthropogenic aerosol emission season is January to March (JFM), the end of the dry season in West Africa. This paper therefore focuses on the anthropogenic WAP in JFM because it is at its most intense in this season and will therefore have its greatest effect at this time. Figure 3 shows the M2 reanalysis JFM AOD data for the WAP Area which was extremely high in 2004, 2007, 2012, and 2016 compared with the intervening years. 


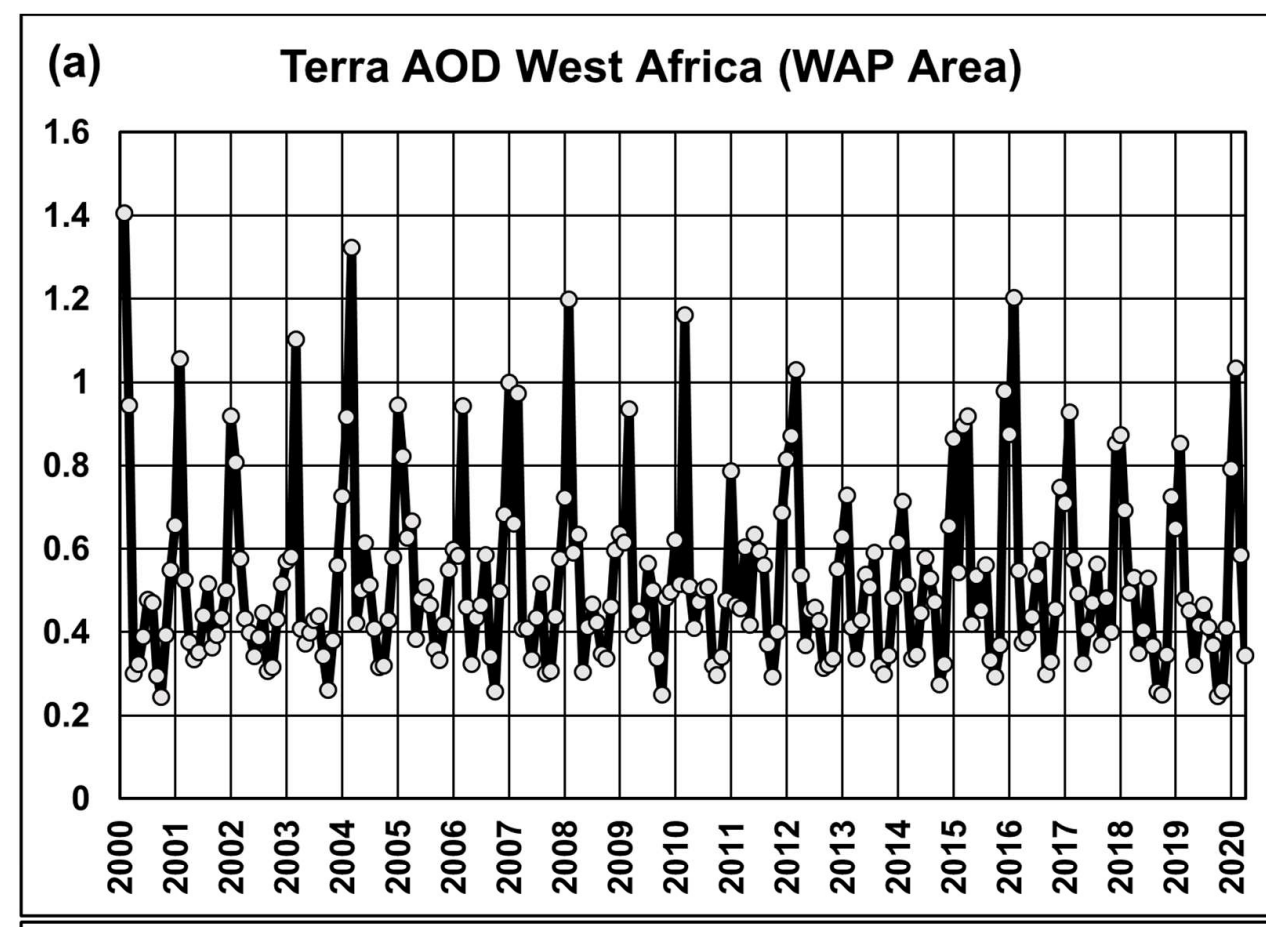

(b) Terra AOD West Africa - Monthly Variation

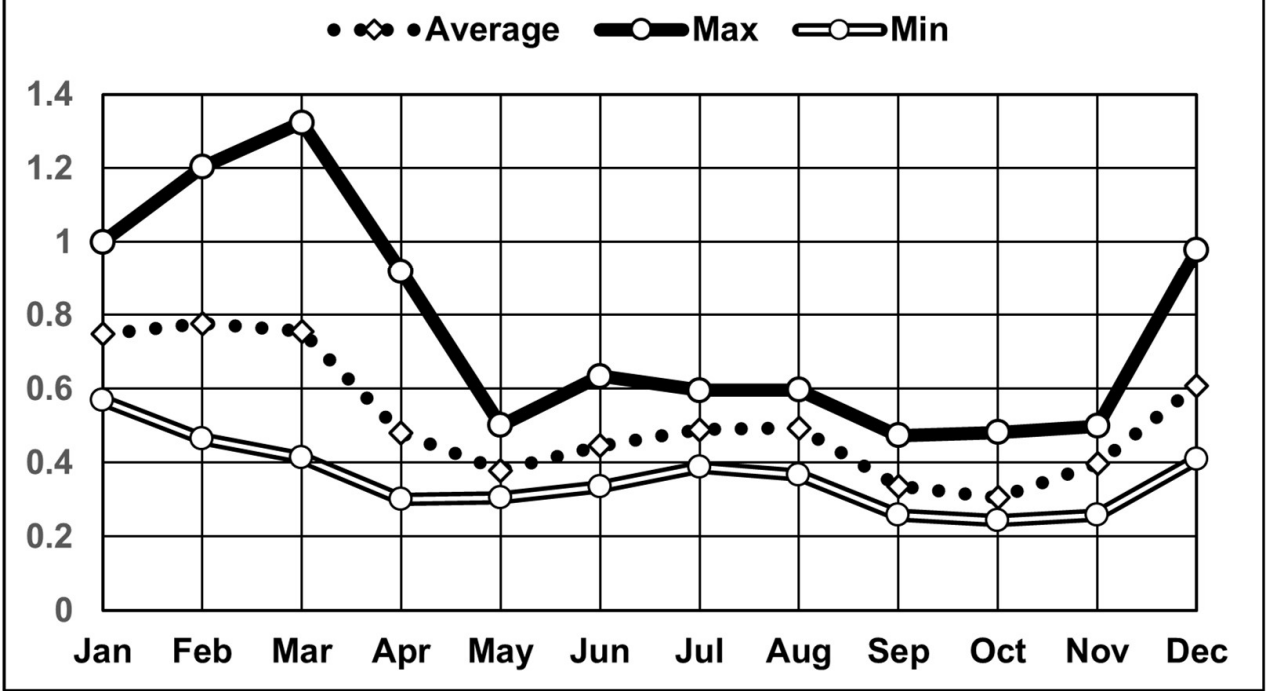

Figure 2. (a) Terra Monthly AOD WAP Area; (b) Average, Max and Min Annual cycle. 


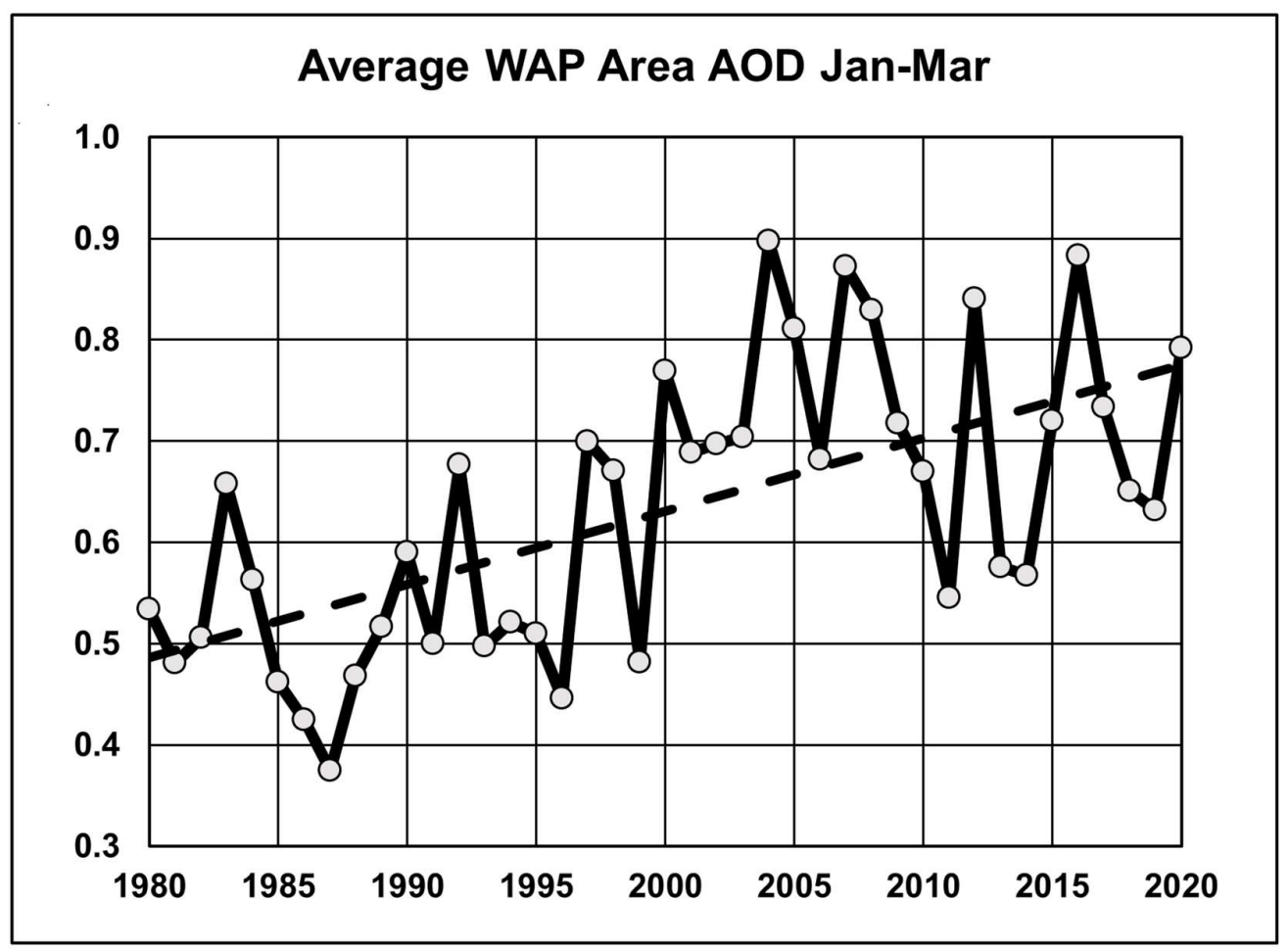

Figure 3. M2 JFM AOD WAP Area.

The maximum Terra AOD for the WAP Area was 1.41 (Feb 2000) and the trend line of the M2 AOD in JFM in the WAP Area increased from 0.5 in 1980 to 0.76 in 2019, a 52\% increase. From 1980 to 2004, a major biomass burning event year, the increase in AOD in March was from 0.37 to 1.10 a near three-fold increase.

Figure 4 shows the geographic extent of the JFM 2004 extreme apparition of the WAP and clearly shows the origin of the plume to be in southern Nigeria as the highest AOD levels are seen there.

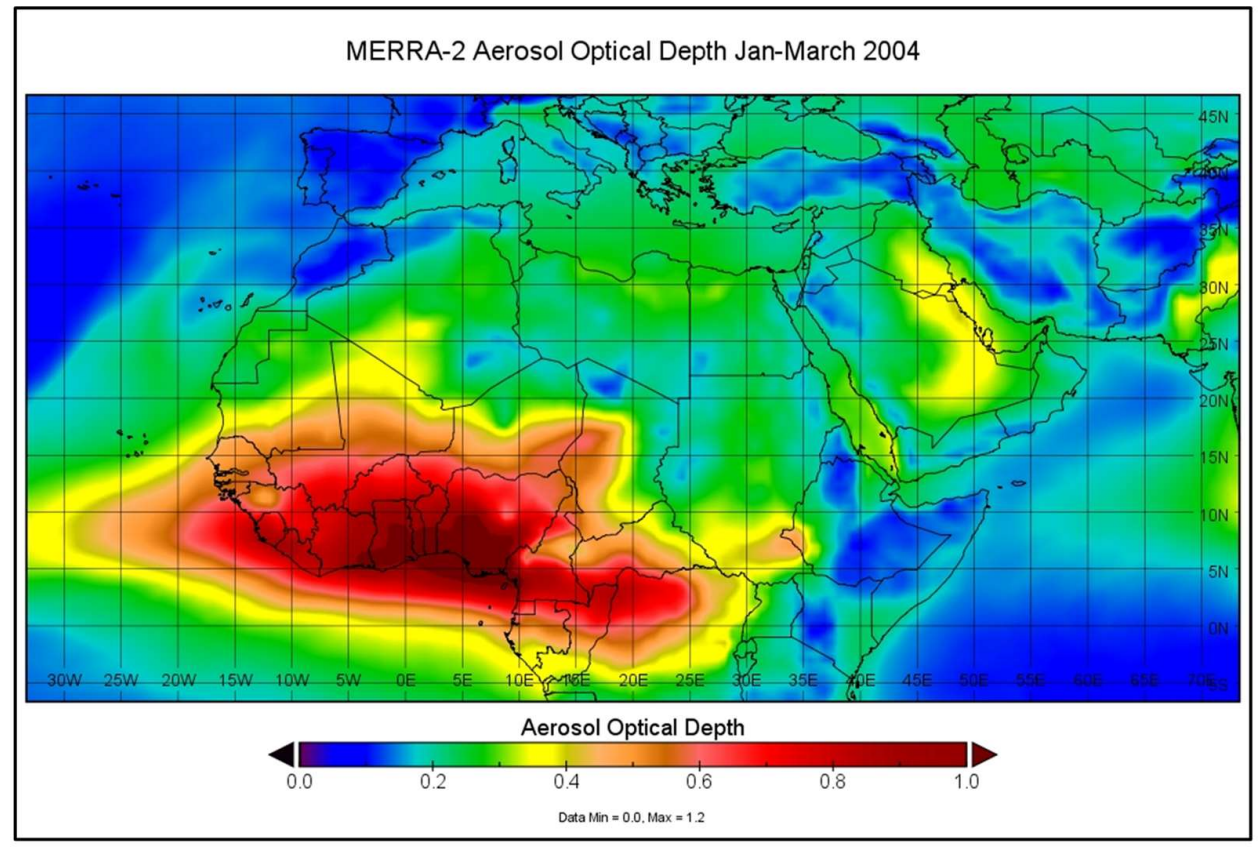

Figure 4. M2 JFM AOD 2004. 
Good correlations, over 0.90 at Ilorin within the WAP Area in Nigeria, were found between AOD retrievals from the NASA Terra and Aqua satellites and ground-based photometers in West Africa [7]. Figure 2 in that report clearly shows the seasonal variation in the AOD levels with many days showing AOD levels at Ilorin over 1.00 in JFM from 2005 to 2009.

WAP History: Figure 3 shows a significant trend in the AOD of the WAP from 1980 to 2020 and the WAP AOD would have been significantly lower in 1950 than it was in 1980 for two reasons:

First: the population of West Africa was significantly higher in 1980 (188 million) c.f. 1950 (71 million) (United Nations World population data for West Africa) which implies less biomass burning from agriculture and land clearing in 1950 and therefore a lower aerosol burden from these sources; and

Second: oil production started in Nigeria in 1958 (Nigerian National Petroleum Corporation in "History of the Nigerian Petroleum Industry" at https://www.nnpcgroup.com/NNPC-Business/Business-Information/Pages/IndustryHistory.aspx ) and there were therefore no aerosol producing gas flares driven by oil production in Nigeria in 1950. Note: Images of gas flares producing aerosols in Nigeria can be found in Google Earth (eg 7.1532 ${ }^{\circ} \mathrm{E} 4.4244^{\circ} \mathrm{N}$ at a major installation in Bonny and at $5.615^{\circ} \mathrm{E} 4.88^{\circ} \mathrm{N}$ in the remote Niger Delta).

The estimated AOD of the WAP in JFM in 1950 is 0.09 on the basis of pro rata population and oil production changes. The same estimate can be derived by projecting the trend of the lower AOD levels in the M2 data back to 1950. This implies the effects of the extreme WAP are very recent and that the anthropogenic WAP probably did not exist in its present extreme state in JFM prior to or even in the early 1960's as oil production did not reach one million barrels per day until 1970 (BP Statistical Review of World Energy 2019) due in part to the Biafran war from 1967 to 1970.

The main sources of aerosols in the WAP are described in detail in Appendix B which clearly shows that they are anthropogenic.

A review of gas flaring aerosols states that: climate models often assume gas flares produce a smokeless flame and therefore underestimate the black carbon emissions from the flares; and the temperature of the flare plume is about $2,000^{\circ} \mathrm{K}$ which can enable the plume to rise into the free troposphere enabling long range transport which is also not well captured in climate models [8].

Personal Note: I lived in southern Nigeria between 1968 and 1972 and saw no extreme levels of smoke in the atmosphere in those years.

\subsection{Aerosols absorb solar radiation, heat the atmosphere, cool the Surface \& Reduce Convection}

Aerosols are reported to absorb solar radiation, heat the atmosphere and reduce surface radiation [9], [10], [11] and [12]. Significant decreases in surface radiation caused by aerosols have been reported:

1. Increasing AOD levels over India have reduced surface radiation by $0.4 \%$ per year from 1995 to 2012 [13];

2. During the 1997 extreme fire event in Indonesia surface radiation reduced by over $46 \mathrm{~W} / \mathrm{m}^{2}$ which caused a reduction in the sea surface temperature of over $1^{\circ} \mathrm{C}$ [14];

3. a $10 \%$ to $30 \%$ reduction of Photosynthetically Active Radiation recorded during INDOEX in the Indian Ocean in 1999 [15];

4. $-150 \mathrm{~W} \mathrm{~m}^{-2}$ in an analysis of the Indonesian wildfires which occurred in 1997 [16]; and

5. Approximately $-286.0\left(\mathrm{~W} / \mathrm{m}^{2}\right) / \tau \alpha$ recorded during the Aerosol Characterization Experiment - Asia in 2001 [17] ( $\tau \alpha$ is the aerosol optical depth and its derivation is described in the paper).

Aerosols have also been shown to reduce convection [18] and [19] at least in part by cooling the surface and warming the atmosphere which stabilises the atmosphere.

Appendix $C$ describes the effects of aerosols on climate in more detail. 


\subsection{Pressure over the Mediterranean and the Iberian Peninsula}

All three changes in the winter climate of Europe are linked to sea level pressure over SEMIEA which, the literature shows, has significantly increased in the winter months in recent decades as Figure 7 in [20] from the NCEP reanalysis, shows. The IPCC noted in AR5 that: atmospheric circulation changes are important drivers of regional climate change; and anthropogenic influences have probably altered regional sea level pressure patterns. This paper demonstrates exactly this for Europe where atmospheric circulation change driven by the anthropogenic WAP creates the increase in pressure over SEMIEA which, in turn, drives the changes in the winter climate of Europe.

Trends in sea-level pressure in Europe are shown in Figure 7 in [20] from 1950-2007 using the NCEP reanalysis and show a significant increase in pressure in the SEMIEA. Comparisons of observed changes and climate model simulations are also included and, whilst some models e.g., the ESSENCE ensemble, show a significant trend, observations are a factor of four higher. Other models show no positive trends. However, [21] shows that the ESSENCE ensemble only includes tropospheric sulphate aerosols and cannot therefore have modelled the WAP correctly as it is predominantly composed of carbonaceous aerosols (Appendix B).

\subsection{Drought in Spain}

The northward displacement of cyclone trajectories in the North Atlantic in winter was a significant driver of the 2004/05 drought in Iberia when only about $40 \%$ of the normal rainfall fell in southern Iberia and the North Atlantic Oscillation and East Atlantic indices could not explain the low precipitation [22].

An investigation into the relationship between the occurrence of drought in NE Spain and atmospheric circulation found an increase in the number of anti-cyclonic days in winter from 1950 to 2000 resulted in lower rainfall in NE Spain [23]. Figure 5 in the paper shows Spain covered by higher than average pressure in winter during these days.

This paper demonstrates why such an increase in sea-level pressure has occurred over Iberia in winter in recent decades and therefore why Iberia has endured an increased frequency of drought.

\subsection{Floods in the United Kingdom}

The United Kingdom (UK) has experienced significant floods in winter and early spring in recent decades with 1998, 2000, 2001, 2002, 2005, 2009, 2010, 2012, 2014, 2015, 2019, 2020 and 2021 noted as significant rainfall/flood events on the UK Met. Office website at https://www.metoffice.gov.uk/weather/learn-about/past-uk-weather-events demonstrating a return frequency of about 2 years. In February 2020 storms Ciara and Dennis unleashed yet more UK floods with Dennis causing an estimated five fatalities in the UK (Mirror https://www.mirror.co.uk/news/uk-news/fears-missing-woman-87-sixth21530531) and the Association of British Insurers estimating the damage from these two storms at $£ 360$ million (https://www.abi.org.uk/news/news-articles/2020/03/insurancepay-outs-to-help-customers-recover-from-storms-ciara-and-dennis-set-to-top-360-million/ ). Determining the cause of such events and why they are of such severity in recent decades is therefore crucial socially, economically and scientifically to enable mitigation action to start.

The literature includes the following analyses of UK floods:

1. The devastating floods since 1990 are without precedent in a 558 year paleorecord of floods derived from Lake Bassenthwaite sediment [24]. This time period coincides with the WAP reaching average aerosol optical depth (AOD) levels from January to March (JFM) consistently above 0.5 in the M2 data;

2. A rapid succession of Atlantic low pressure systems crossed the UK in the winter of 2013-14 with large increases in rainfall in the south of England and much of Scotland [25]. This reference suggested further work is needed to determine the effects of aerosols on tropical circulation and this is the focus of my paper; 
3. The 2014-15 floods were also investigated with a regional climate model covering the UK and eastern North Atlantic Ocean to investigate the effects of anthropogenic emissions on the winter climate of the UK [26]. However, the only mention of aerosols in the paper refers to sulphate aerosol precursors and it cannot therefore have included the carbonaceous aerosols which constitute the WAP (Appendix B) which this paper addresses. The paper noted that more work is required to clearly identify which human influence is creating these changes rather than just attributing them to climate change. Which, again, is exactly what this paper does;

4. Atmospheric rivers flowing from the subtropical Atlantic preceded the ten largest winter flood events in British river basins with the SW-NE tilt in the large-scale atmospheric flow being crucial [27]. Figure 2(b) in the paper shows high pressure over SEMIEA which this paper demonstrates is created by the WAP.

\subsection{Higher Winter Temperatures in Northern Europe}

The Intergovernmental Panel on Climate Change (IPCC) has identified Europe as one of the fastest warming regions of the world in Assessment Report 4 (AR4) discussing changes since 1979. The IPCC AR5, citing [28] and [29], stated that European temperatures are distinctly warmer than would be expected for similar atmospheric flow regimes in the past.

The European autumn and winter of 2006-07 was exceptionally warm and the New Scientist reported that the temperatures in each of these months were probably the warmest in 500 years but the combination of two such warm months was probably the first since 1289 citing [30]. The winter temperature rise in Europe is dominated by circulation changes that bring mild maritime air into Europe north of the Alps [20] based on [31] and, the climate modelling reviewed in the paper fails to replicate these circulation changes specifically the higher pressure over the SEMIEA. Regional temperature change has been strongly influenced by aerosols and changes in regional precipitation should be more sensitive to aerosol forcing than greenhouse gas forcing [32] and this paper confirms both these statements for Europe.

Figure 7(a) in [20] shows the high-pressure anomaly. Such an area of persistent highpressure over the SEMIEA advects warm air from the central Atlantic to northern Europe, resulting in anomalously high temperatures as noted in the paper.

These cited papers demonstrate that the climate modelling which was reviewed does not include the forcing agent which caused the rise in pressure over SEMIEA which this paper shows to be the anthropogenic, carbonaceous WAP.

\section{METHOD and DATA}

The data sources are shown in Appendix D and the data was detrended using PAST 3 [33] which removes linear trends in data by subtracting a linear regression line from the values. The average of the un-detrended data was then added back to the detrended values to give values consistent with the magnitude of the un-detrended data which enables comparisons between the datasets and with observations.

\subsection{Last Millennium Ensemble}

\subsubsection{LME Model}

The LME model and the treatment of aerosols is described in Appendix E.

\subsubsection{LME Initial Processing}

The LME data used is: LME project, atmosphere, post processed data, monthly averages and consists of the seven simulations from 850 to 2005 CE shown in Table 1 of [3] and one simulation named "850 forcing" which were repeated in multiple runs. These simulations were used in this analysis with the run number in (): 850 (003); Green House Gas (003); Orbital (003) Land Use (003); Solar (005); Volcanic (005); Ozone \& Aerosols (002); All forcing (013).

The following global data was downloaded for each simulation/run listed above: AOD (AODVIS); surface pressure (PSL), surface temperature (TS); precipitation (PRECL) 
and vertical pressure velocity (omega). Data for the required regions e.g., WAP Area AOD was extracted from the data files as a time series of 13,872 months.

Each simulation/run was processed separately to give January to March (JFM) average data for each parameter: AOD; PSL; TS; PRECL; and omega for the required areas. Annually averaged data was also calculated for AOD and omega. The other data was then correlated with the AOD data from the same simulation/run.

\subsection{MERRA-2 Data}

The M2 data is used as an independent dataset in two ways:

1. To replicate and confirm the analysis of the LME data;

2. To show the changes in the various parameters in a year of high WAP AOD (2004) compared with a year of low WAP AOD (1987). These visualisations show clearly the geographical extent of the effects of the WAP in all the parameters analysed.

\subsection{Terra and NCEP (TN) Data}

The TN data is used to provide real world data analysis of the effects of the WAP and confirm the LME analysis. The Terra data is derived directly from the MODIS sensor on the Terra satellite and the NCEP data is used in [20] as the comparison data for the anomalous high pressure over SEMIEA.

\section{RESULTS}

The results are presented in three ways: scatter plots; difference plots; and Tables and follow the stages described in the introduction.

The first scatter plots (a) in each section show:

1. All the data from the eight LME simulations/runs combined, a total of 8,248 data points;

2. The segmented data from all the LME simulations averaged in bins from AOD less than 0.45 in steps of 0.05 to 0.90 and over 0.9 ;

3. The M2 reanalysis from 1980 to 2020;

4. The TN data from 2000 to 2020; and

5. The trend line, trend line equation and correlation magnitude squared for each dataset.

The second scatter plots (b) in each section show the eight LME simulations individually and include the items in 5 above. To separate the data the following constant was added to the AOD is each simulation: 850 0.0; All 0.2; Aero 0.4; GHG 0.6; Land 0.8; Orbital 1,0; Solar 1.2; and Volcano 1.4.

The difference plots are generated from the M2 or NCEP datasets by subtracting the 1987 data from the 2004 data using NASA Panoply or the NCEP website.

Table 1 shows results from the combined LME simulations for each parameter:

1. The JFM detrended time series correlations extracted from the graphs;

2. The trend per unit AOD increase in the WAP extracted from the graphs;

3. The change over the AOD range in that dataset;

4. The change from the estimated 1950 AOD to the maximum AOD level;

5. The percentage change in each dataset for rainfall changes from the estimated 1950 AOD to the maximum AOD in the dataset.

Table 2 shows the correlation of the WAP AOD and each parameter from the individual simulations and the change in the parameter per unit AOD increase in each simulation.

In Tables 1 and 2 all the LME correlations show significance less than 0.01 and, in the LME segmented data, very much less than 0.01 due to the magnitude of the correlation.

In Table 2 the trends show minimal variation across the eight forcings with only four significant outliers out of 96: All Forcing WAP Omega; and Aero Forcing UK PRECL. 
Table 1. Correlations, trend and changes from: minimum to maximum JFM AOD; and from the estimated 1950 JFM AOD to maximum JFM AOD for the parameters shown in the LME, MERRA-2 and TN datasets. Significance is $<0.10$ Underline, $<0.05$ Italic, $<0.02$ Bold Italic, $<0.01$ Bold.

\begin{tabular}{|c|c|c|c|c|c|}
\hline A & Surface Temp W Africa & LME & LME(S) & MERRA-2 & Terra NCEP \\
\hline 1 & $\mathrm{R}$ & -0.66 & -0.99 & -0.22 & -0.14 \\
\hline 2 & $\mathrm{R}^{2}$ & 0.43 & 0.99 & 0.05 & 0.02 \\
\hline 3 & Trend/unit AOD ( $\left.{ }^{\mathrm{o}} \mathrm{K}\right)$ & -3.06 & -3.10 & -1.63 & -0.45 \\
\hline 4 & Change over AOD range $\left({ }^{\circ} \mathrm{K}\right)$ & -3.15 & -1.62 & -0.66 & -0.23 \\
\hline 5 & 1950 AOD to max AOD ( $\left.{ }^{\circ} \mathrm{K}\right)$ & -3.63 & -2.65 & -1.27 & -0.45 \\
\hline B & Omega W Africa & & & & \\
\hline 1 & $\mathrm{R}$ & 0.71 & 0.99 & 0.54 & 0.48 \\
\hline 2 & $\mathrm{R}^{2}$ & 0.50 & 0.99 & 0.29 & 0.23 \\
\hline 3 & Trend/unit AOD $(\mathrm{Pa} / \mathrm{s})$ & 0.05 & 0.05 & 0.08 & 0.07 \\
\hline 4 & Change over AOD range $(\mathrm{Pa} / \mathrm{s})$ & 0.05 & 0.03 & 0.03 & 0.04 \\
\hline 5 & 1950 AOD to max AOD (Pa/s) & 0.06 & 0.04 & 0.06 & 0.07 \\
\hline C & MSLP SEMIEA & & & & \\
\hline 1 & $\mathrm{R}$ & 0.75 & 0.99 & $\underline{\underline{0.28}}$ & 0.60 \\
\hline 2 & $\mathrm{R}^{2}$ & 0.56 & 0.99 & $\underline{0.08}$ & 0.36 \\
\hline 3 & Trend/unit AOD (hPa) & 13.17 & 13.15 & 5.49 & 15.04 \\
\hline 4 & Change over AOD range (hPa) & 13.54 & 7.44 & 2.87 & 7.54 \\
\hline 5 & 1950 AOD to max AOD (hPa) & 15.60 & 11.59 & 4.43 & 14.90 \\
\hline $\bar{D}$ & Rainfall MIEA & & & & \\
\hline 1 & $\mathrm{R}$ & -0.64 & 0.99 & -0.42 & -0.54 \\
\hline 2 & $\mathrm{R}^{2}$ & 0.41 & 0.98 & 0.18 & 0.29 \\
\hline 3 & Trend/unit AOD (mm) & -189 & -189 & -186 & -243 \\
\hline 4 & Change over AOD range $(\mathrm{mm})$ & -194 & -107 & -75 & -122 \\
\hline 5 & 1950 AOD to max AOD (mm) & -224 & -166 & -145 & -241 \\
\hline 6 & Percentage change from 1950 & $-97 \%$ & $-72 \%$ & $-58 \%$ & $-75 \%$ \\
\hline$E$ & Rainfall UK & & & & \\
\hline 1 & $\mathrm{R}$ & 0.42 & 0.98 & 0.10 & 0.47 \\
\hline 2 & $\mathrm{R}^{2}$ & 0.18 & 0.96 & 0.01 & 0.22 \\
\hline 3 & Trend/unit AOD (mm) & 236 & 236 & 24 & 157 \\
\hline 4 & Change over AOD range $(\mathrm{mm})$ & 243 & 134 & 13 & 79 \\
\hline 5 & 1950 AOD to max AOD (mm) & 280 & 208 & 19 & 156 \\
\hline 6 & Percentage change from 1950 & $72 \%$ & $54 \%$ & $8 \%$ & $197 \%$ \\
\hline$F$ & Temperature Europe & & & & \\
\hline 1 & $\mathrm{R}$ & 0.45 & 0.99 & 0.33 & 0.28 \\
\hline 2 & $\mathrm{R}^{2}$ & 0.20 & 0.98 & 0.11 & 0.08 \\
\hline 3 & Trend/unit AOD $\left({ }^{\circ} \mathrm{K}\right)$ & 2.45 & 2.43 & 3.68 & 2.76 \\
\hline 4 & Change over AOD range $\left({ }^{\circ} \mathrm{K}\right)$ & 2.52 & 1.38 & 1.48 & 1.38 \\
\hline 5 & 1950 AOD to max AOD ( $\left.{ }^{\circ} \mathrm{K}\right)$ & 2.90 & 2.14 & 2.87 & 2.73 \\
\hline
\end{tabular}


Table 2. Correlations and trend of the eight LME Simulations. Significance is Bold $<0.01$.

\begin{tabular}{|lcccccccc|}
\hline Correlation & $\mathbf{8 5 0}$ & All & Aero & GHG & Land & Orbital & Solar & Volcano \\
\hline WAP TS & $\mathbf{- 0 . 6 8}$ & $\mathbf{- 0 . 6 2}$ & $\mathbf{- 0 . 6 6}$ & $\mathbf{- 0 . 6 4}$ & $\mathbf{- 0 . 6 7}$ & $\mathbf{- 0 . 6 8}$ & $\mathbf{- 0 . 6 9}$ & $\mathbf{- 0 . 6 6}$ \\
WAP Omega & $\mathbf{0 . 7 3}$ & $\mathbf{0 . 6 1}$ & $\mathbf{0 . 7 4}$ & $\mathbf{0 . 7 3}$ & $\mathbf{0 . 7 3}$ & $\mathbf{0 . 7 5}$ & $\mathbf{0 . 7 7}$ & $\mathbf{0 . 7 2}$ \\
SEMIEA PSL & $\mathbf{0 . 7 5}$ & $\mathbf{0 . 7 3}$ & $\mathbf{0 . 7 5}$ & $\mathbf{0 . 7 6}$ & $\mathbf{0 . 7 5}$ & $\mathbf{0 . 7 5}$ & $\mathbf{0 . 7 7}$ & $\mathbf{0 . 7 4}$ \\
MIEA PRECL & $\mathbf{- 0 . 6 3}$ & $\mathbf{- 0 . 6 2}$ & $\mathbf{- 0 . 6 2}$ & $\mathbf{- 0 . 6 4}$ & $\mathbf{- 0 . 6 6}$ & $\mathbf{- 0 . 6 3}$ & $\mathbf{- 0 . 6 6}$ & $\mathbf{- 0 . 6 3}$ \\
UK PRECL & $\mathbf{0 . 4 5}$ & $\mathbf{0 . 4 2}$ & $\mathbf{0 . 3 3}$ & $\mathbf{0 . 3 9}$ & $\mathbf{0 . 4 4}$ & $\mathbf{0 . 4 0}$ & $\mathbf{0 . 4 4}$ & $\mathbf{0 . 4 6}$ \\
Europe TS & $\mathbf{0 . 4 4}$ & $\mathbf{0 . 4 7}$ & $\mathbf{0 . 4 4}$ & $\mathbf{0 . 4 5}$ & $\mathbf{0 . 4 7}$ & $\mathbf{0 . 4 2}$ & $\mathbf{0 . 4 7}$ & $\mathbf{0 . 4 6}$ \\
\hline Trends per unit AOD & & & & & & & -3.09 & -3.10 \\
\hline WAP TS (ㅇ) & -3.18 & -2.82 & -3.03 & -3.05 & -3.12 & -3.07 & -3.09 \\
WAP Omega (Pa/s) & 0.0484 & 0.0395 & 0.0530 & 0.0478 & 0.0483 & 0.0493 & 0.0514 & 0.0493 \\
SEMIEA PSL (hPa) & 13.66 & 12.70 & 12.55 & 13.57 & 13.33 & 12.58 & 13.68 & 12.92 \\
MIEA PRECL (mm) & -188 & -179 & -172 & -193 & -201 & -182 & -195 & -187 \\
UK PRECL (mm) & 265 & 234 & 180 & 217 & 250 & 211 & 240 & 250 \\
Europe TS (으) & 2.45 & 2.54 & 2.30 & 2.42 & 2.64 & 2.05 & 2.60 & 2.54 \\
\hline
\end{tabular}

\subsection{Stage 1: The WAP Forms}

The intense WAP forms in late December and disperses in April as Figure 2 shows and this paper focuses on JFM when the WAP is at the most extreme level. Figure 5 shows the extreme WAP in JFM in 2004 compared to the 1987 apparition with a significant increase in AOD of over 0.6 across half of the WAP Area.

It is worth noting that the range of JFM AOD in the three datasets is Terra 0.6 to 1.2, M2 0.4 to 0.9 and the LME 0.2 to 1.1. The LME and M2 AOD ranges are similar whilst the Terra dataset (2000 to 2020) shows a higher low value than the others as the WAP was well established for the entire Terra dataset and was not for the LME and M2 data as Figures 2 and 3 show.

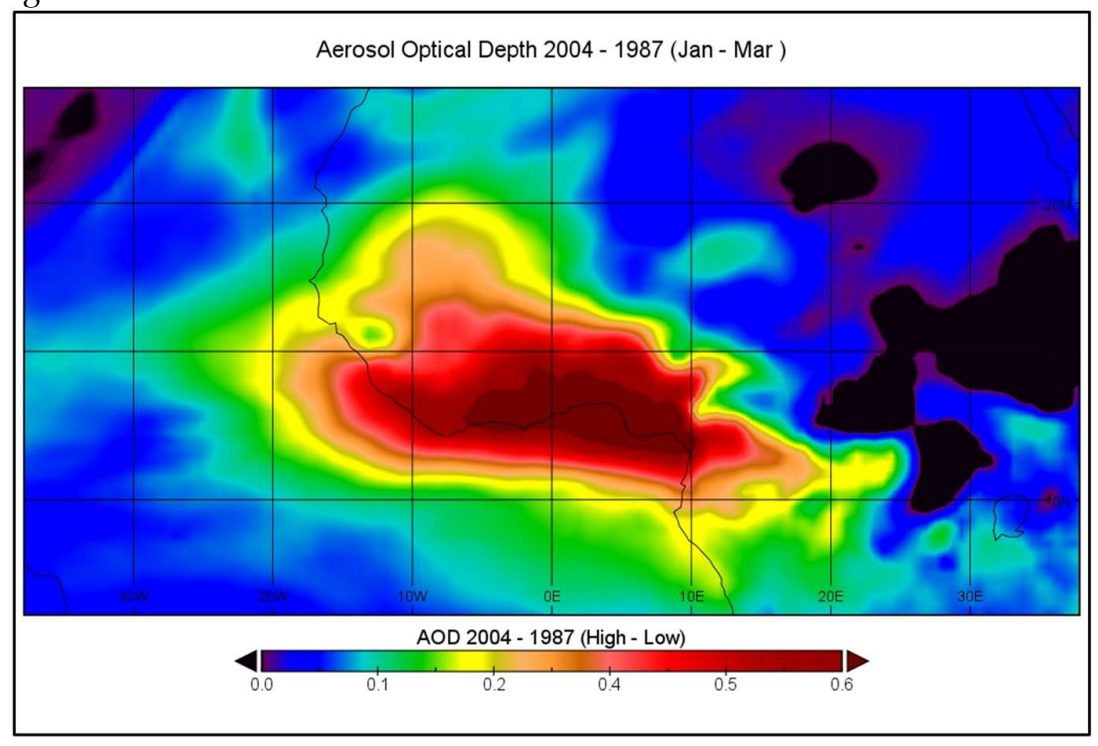

Figure 5. M2 JFM AOD 2004 minus1987

\subsection{Stage 2: The WAP absorbs Solar Radiation and Heats the Atmosphere}

Figure 6 shows the 2004 minus 1987 M2 air temperature averaged across the WAP Area longitudes from $20^{\circ} \mathrm{S}$ to $40^{\circ} \mathrm{N}$ and it can be clearly seen that in the high AOD year 
the air temperature within the plume at $700 \mathrm{hPa}$ to $850 \mathrm{hPa}$ is higher which correlates reasonably well with estimated aerosol height from the CALIPSO data [34] which on 1 January 2016 (a high AOD year in the WAP Area) showed elevated aerosol levels at altitudes from 1.0 to $5.0 \mathrm{~km}$.

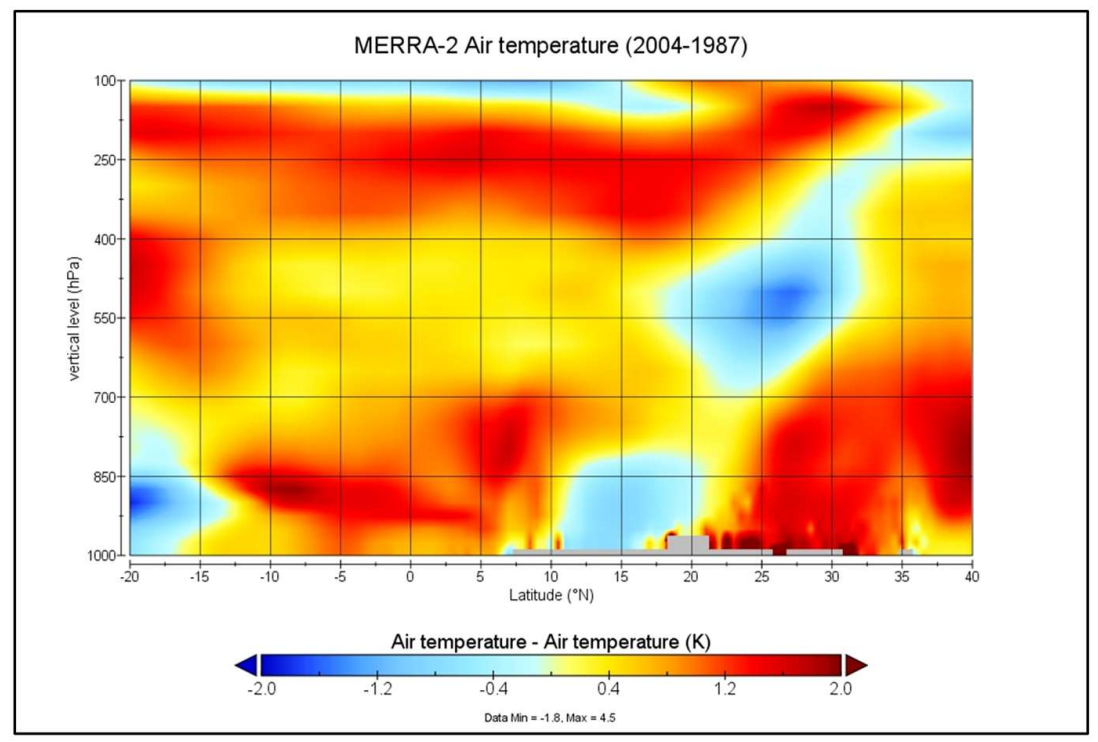

Figure 6. M2 JFM Air Temperature averaged across the WAP Area Longitudes. 2004 minus 1987

\subsection{Stage 3: The WAP Reduces the WAP Land Area Surface Temperature}

The LME data in Table 1 (A)(1-2) and Figure 7(a) show a statistically significant connection between the WAP AOD and the West African surface temperature. The eight individual simulations in Table 2 and Figure 7(b) show an average reduction in temperature of $3.06^{\circ} \mathrm{K}$ per unit AOD increase and an average correlation of -0.66 (significance $<0.01$ ).

Whilst not showing statistical significance, the M2 and TN trend data in Table 1 and Figure 7(a) also show reductions in surface temperature as the AOD rises, and support the LME data. Figure 8 shows a reduction of over $2^{\circ} \mathrm{K}$ over land from the low AOD in 1987 to the high in 2004 which is in good agreement with a 0.6 AOD increase in the LME data which would create a $0.6^{*} 3.06=1.84^{\circ} \mathrm{K}$ 


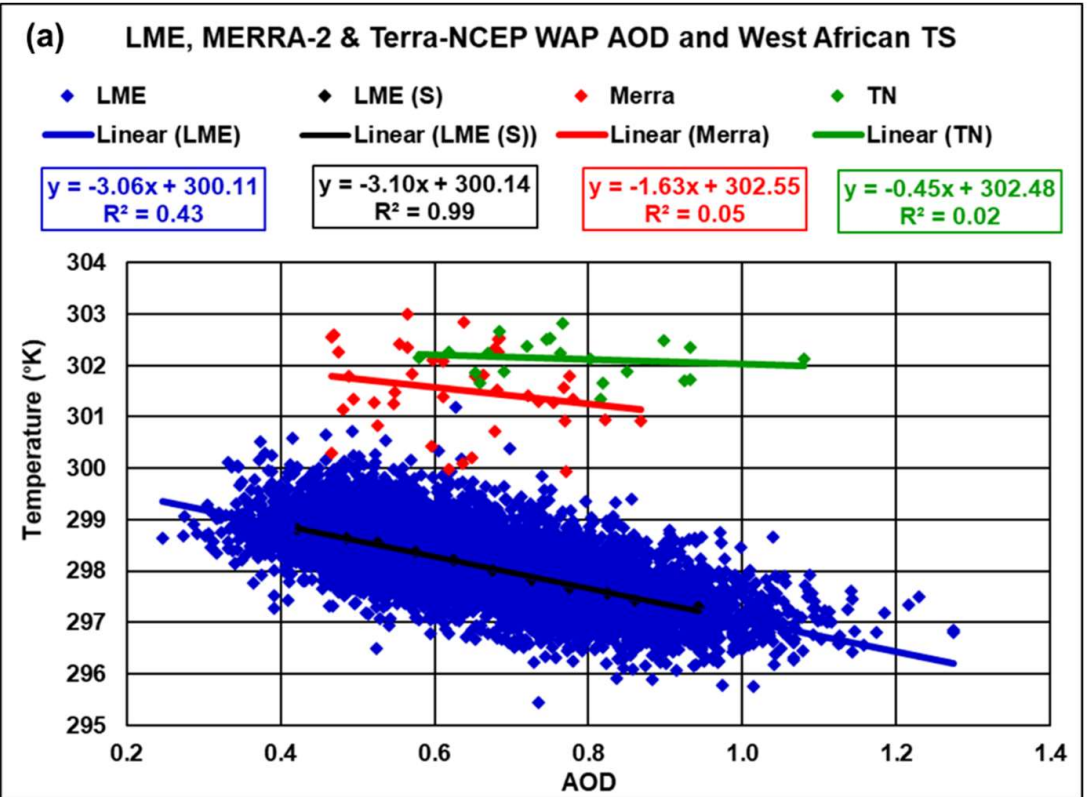

(b) LME Simulations with 0.2 AOD Separation and West African TS

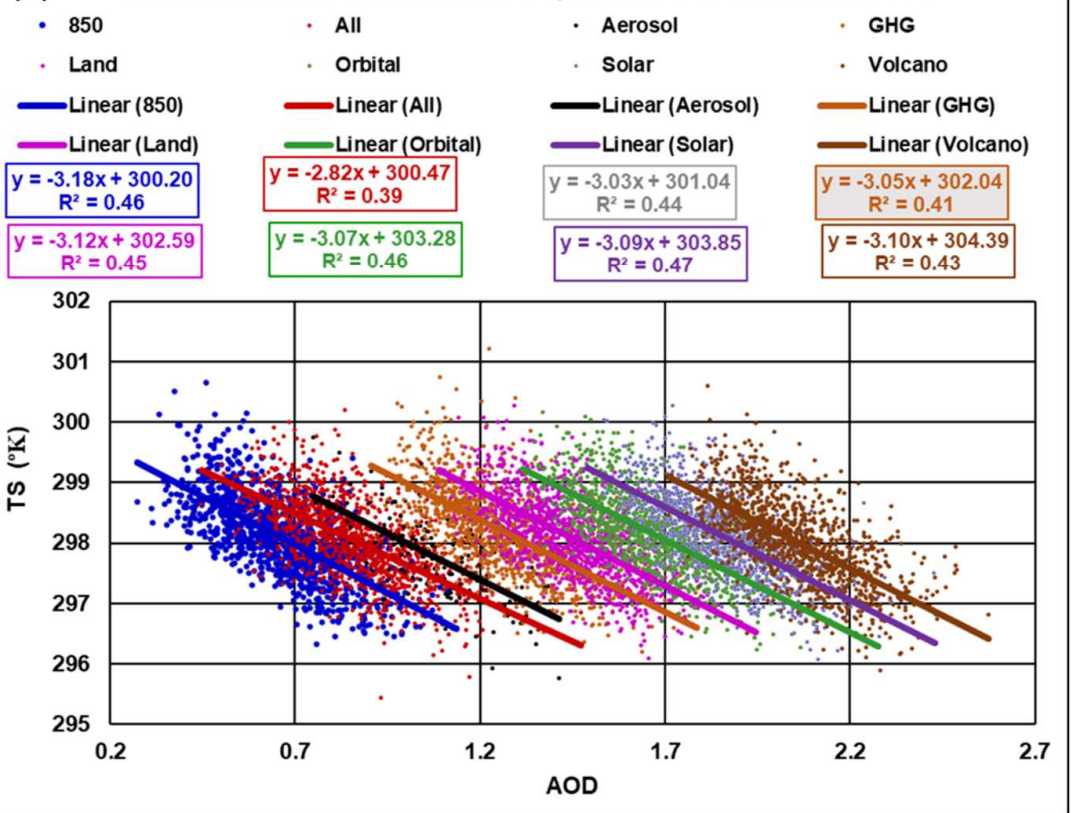

Figure 7. JFM Surface Temperature West Africa and WAP Area AOD. (a) LME, M2 and TN and (b) the eight Individual LME Simulations separated by adding a constant 0.0, 0.2, 0.4, 0.6. 0.8. 1.0, 1.2 and 1.4 to the AOD of the Simulations 


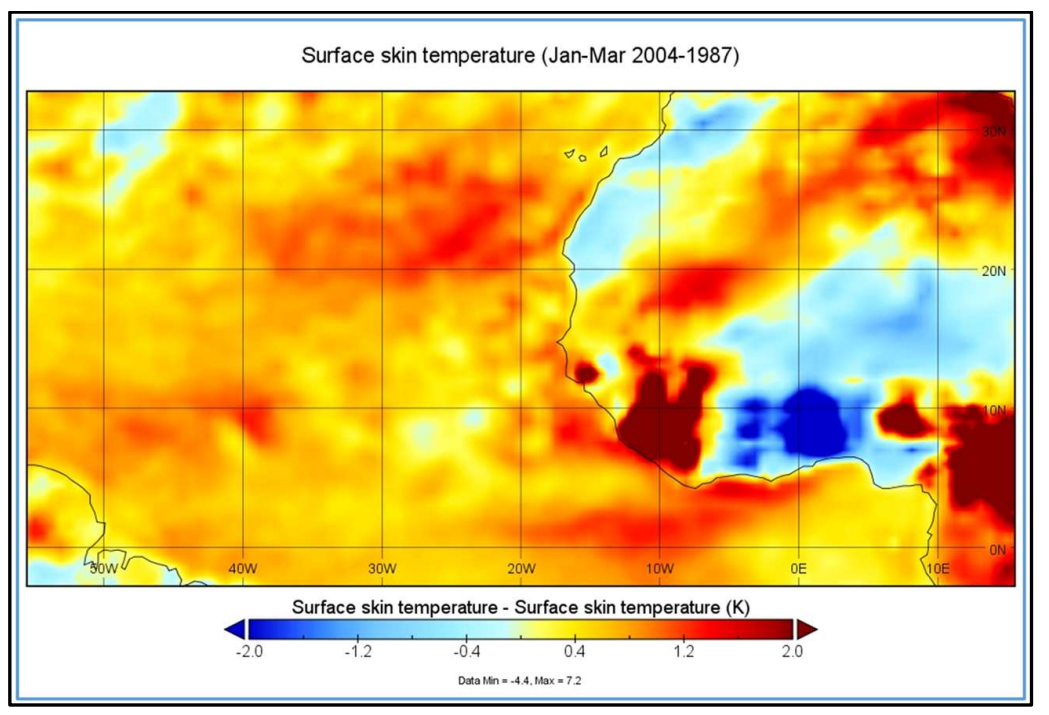

Figure 8. M2 JFM Surface Skin Temperature (TS) 2004 minus 1987

\subsection{Stage 4: The WAP Reduces Convection in West Africa}

The LME, M2 and TN data in Table 1 (B)(1-2) and Figure 9(a) all show a statistically significant connection between the WAP AOD and omega at $820 \mathrm{hPa}$ in West Africa. All datasets at (B)(3-5) and Figure 9(a) show positive increases in omega and thus reductions in convection as the WAP AOD level increases and it is worth noting that:

1. Both the M2 and TN data show higher trends per unit AOD than the LME;

2. The trend line in the LME data in Figure 9(a) shows that, on average, when the WAP $\mathrm{AOD}$ rises over 0.8 , omega becomes positive implying that convection reverses at this level in the model; and

3. Figure 10 shows a $0.03 \mathrm{~Pa} / \mathrm{s}$ increase in omega between 1987 and 2004 in the M2 data.

The LME individual simulations in Table 2 and Figure 9(b) show an average increase in omega of $0.0484 \mathrm{~Pa} / \mathrm{s}$ per unit AOD increase and an average correlation of 0.72 (significance $<0.01$ ).

Note: omega is vertical pressure velocity, and rising air therefore has a negative velocity as it is moving from higher to lower pressure. A reduction in convection is therefore a positive change in omega and as aerosols reduce convection in the WAP Area the correlations of omega and AOD are positive.

In Figure 9 the LME annual data has been included to demonstrate how averaging the effects of aerosol plumes annually, when the extreme plume only exists for a few months, completely destroys the significant effects of the plume. The annually averaged data shows: $\mathrm{R}^{2}$ values an order of magnitude less than the JFM values; omega only rising from -0.019 to -0.013 ; and no reversal of the convection seen in the JFM data as it is masked by the averaging process. This conclusively demonstrates that aerosols must be modelled at spatial and temporal resolutions which can correctly model the plume. The effects of carbonaceous aerosols on convection and atmospheric circulation have been extensively described in the literature as discussed in the introduction and Appendix C. The WAP absorbs solar radiation which warms the upper atmosphere and reduces solar radiation at the surface which cools the lower atmosphere. This alters the vertical temperature profile of the atmosphere with warmer air above cooler air (relative to the temperatures without the plume) and this stabilises the atmosphere and reduces convection. This well understood process is confirmed in the WAP Area in this paper with: the demonstrated correlation of omega with the WAP AOD in Table 1(B)(1-2); Table 2; Figure 9 (a) and (b); and in Figure 10. 


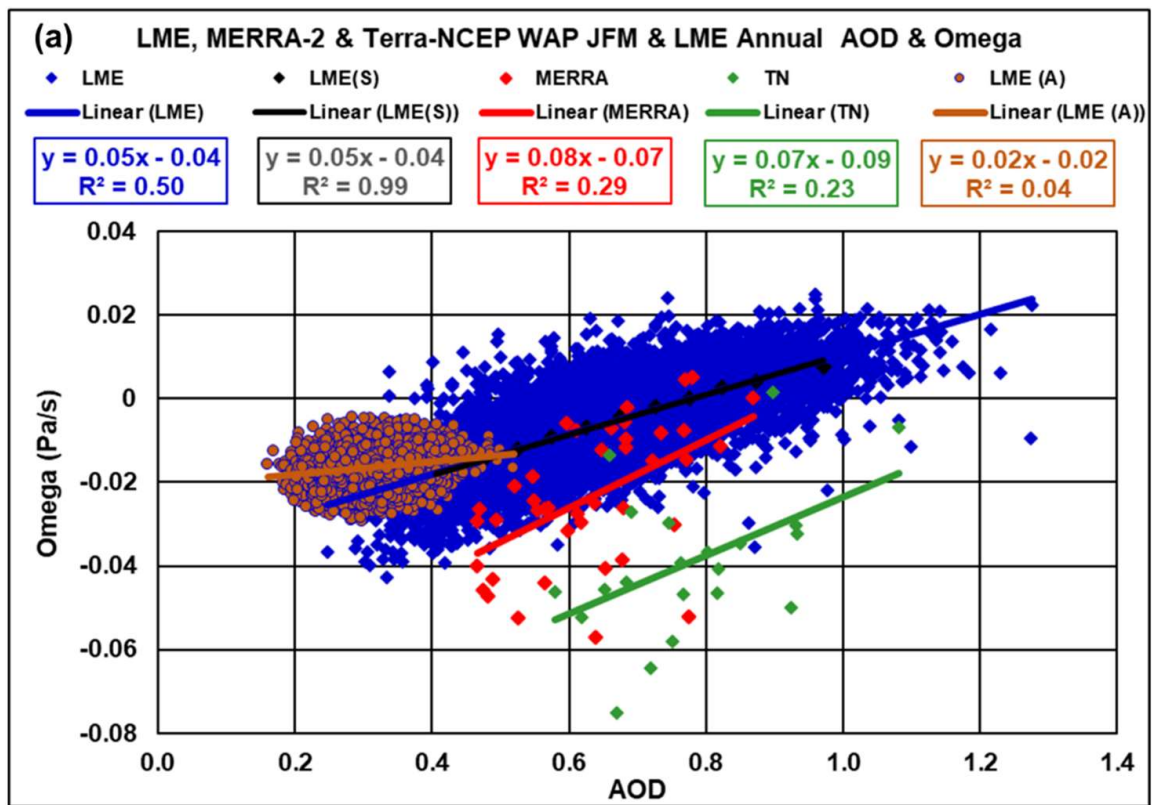

(b) LME Simulations with 0.2 AOD Separation and W.African Omega

\begin{tabular}{|c|c|c|c|}
\hline - 850 & - All & - Aerosol & . GHG \\
\hline - Land & - Orbital & Solar & - Volcano \\
\hline - Linear (850) & Linear (All) & Linear (Aerosol) & Linear (GHG) \\
\hline Linear (Land) & Linear (Orbital) & Linear (Solar) & Linear (Volcano) \\
\hline $\begin{array}{c}y=0.0484 x-0.0367 \\
R^{2}=0.5277\end{array}$ & $\begin{array}{c}y=0.0395 x-0.0394 \\
R^{2}=0.3737\end{array}$ & $\begin{array}{c}y=0.0530 x-0.0618 \\
R^{2}=0.5545\end{array}$ & $\begin{array}{c}y=0.0478 x-0.0653 \\
R^{2}=0.5403\end{array}$ \\
\hline $\begin{array}{c}y=0.0483 x-0.0747 \\
R^{2}=0.5266\end{array}$ & $\begin{array}{c}y=0.0493 x-0.0877 \\
R^{2}=0.5664\end{array}$ & $\begin{array}{c}\mathrm{y}=0.0514 x-0.1050 \\
\mathrm{R}^{2}=0.5890\end{array}$ & $\begin{array}{c}y=0.0493 x-0.1060 \\
R^{2}=0.5216\end{array}$ \\
\hline
\end{tabular}

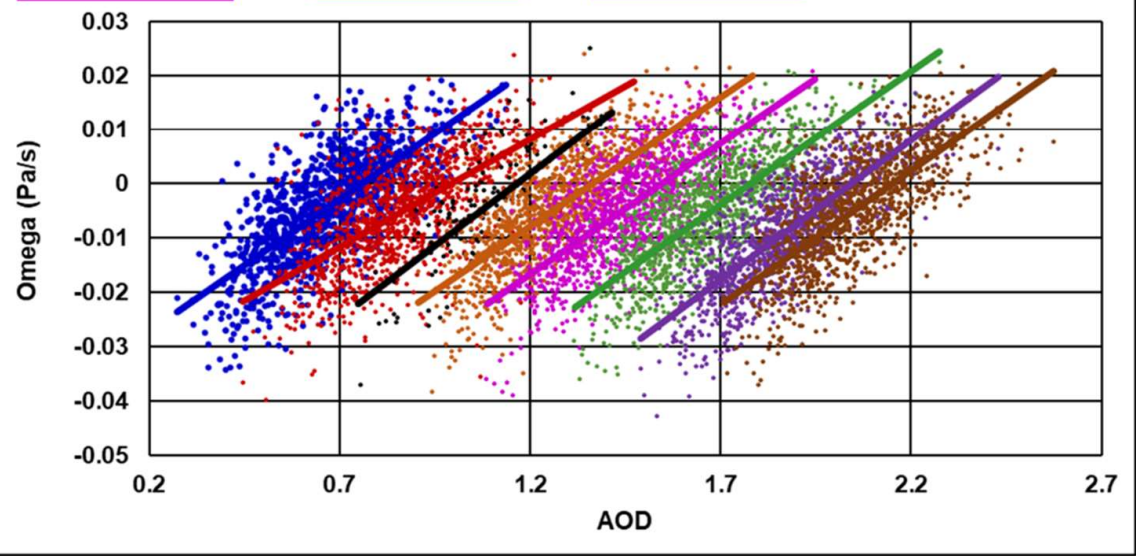

Figure 9. JFM Omega and WAP Area AOD. (a) LME, M2 and TN with LME annual data and (b) the eight Individual LME Simulations separated by adding a constant $0.0,0.2,0.4,0.6 .0 .8 .1 .0,1.2$ and 1.4 to the AOD of the Simulations. 


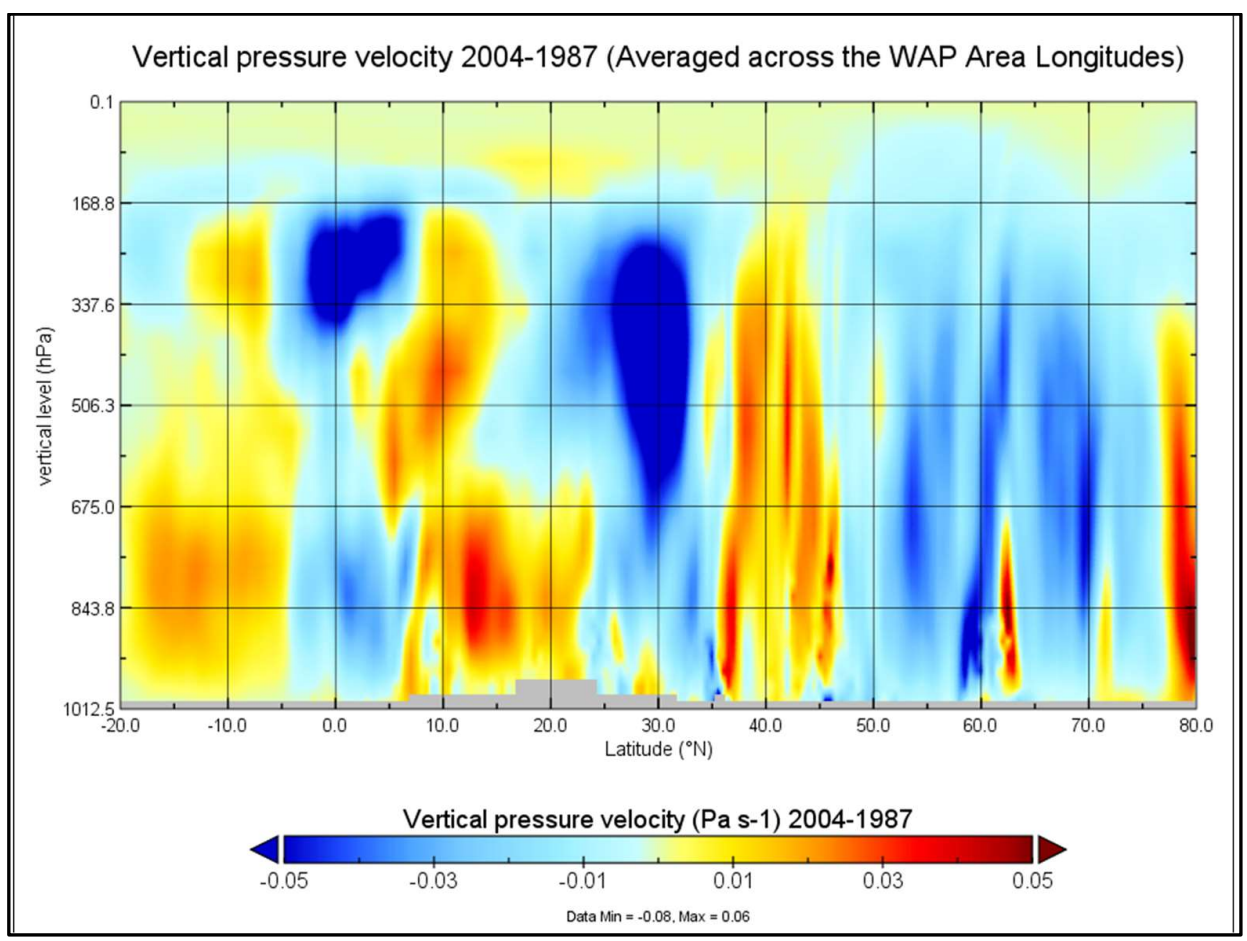

Figure 10. M2 JFM Omega 2004 minus 1987.

\subsection{Stage 5 and 6: The WAP Perturbs the Hadley Circulation}

The Hadley Cells are thermally driven [35], [36] and [37] and reduced JFM surface solar radiation in the WAP Area, combined with no change to the north, results in the highest surface solar radiation in West Africa in JFM moving north and, as the Hadley Cells are thermally driven, the Hadley Circulation moves north.

The change in surface radiation when the WAP is present is shown in Figure 11 using the M2 clear-sky surface radiation and AOD data from the south pole to the north averaged across the WAP Area longitudes with 1987, the lowest WAP Area JFM AOD, data subtracted from 2004, the highest, to show the anomaly in 2004. The two series correlate at -0.98 (significance $<<0.01$ due to the size of the correlation coefficient and number of samples (361)), and it is clear that the increase in AOD in 2004 has caused a reduction in surface radiation of up to $37 \mathrm{~W} / \mathrm{m}^{2}$ and that from $6.75^{\circ} \mathrm{S}$ to $12.25^{\circ} \mathrm{N}$ the reduction averages $21.2 \mathrm{~W} / \mathrm{m}^{2}$. This is an order of magnitude greater and of opposite sign to the total anthropogenic radiative forcing found in the IPCC AR4 $\left(1.6 \mathrm{~W} / \mathrm{m}^{2}\right)$ and AR5 $\left(2.29 \mathrm{~W} / \mathrm{m}^{2}\right)$ over a significant area of the tropics. 


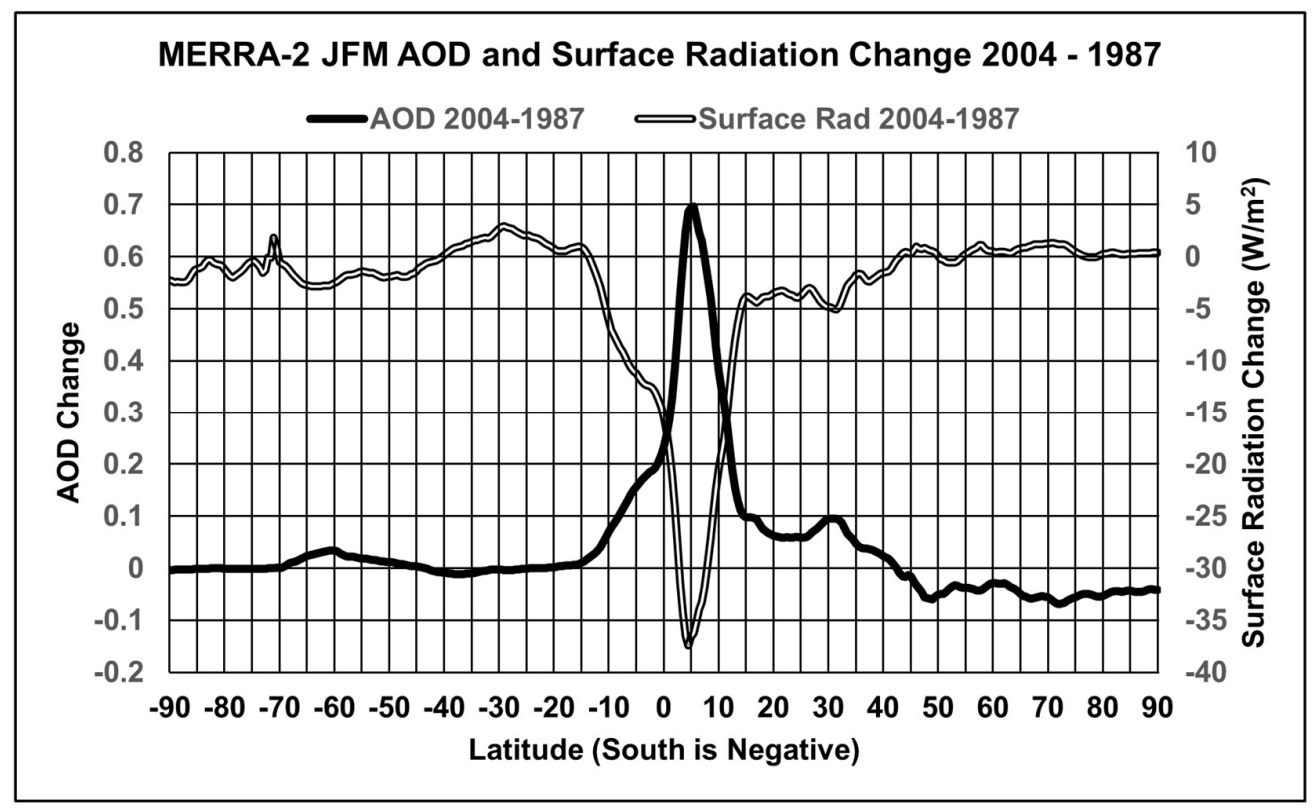

Figure 11. M2 JFM clear sky surface solar radiation and WAP AOD averaged across the WAP Area longitudes. 1987 data (lowest AOD year) subtracted from 2004 (highest AOD Year).

This $21.2 \mathrm{~W} / \mathrm{m}^{2}$ reduction implies that across the WAP Area alone, 1,104 by $1,109 \mathrm{~km}$, (estimated in Google Earth) the total reduction in surface radiation is $2.6 \times 10^{13} \mathrm{~W}$ and would be significantly greater when calculated across the entirety of the plume shown in Figure 4 . This is a dramatically large change in the surface radiation budget, well capable of modifying the atmospheric circulation system as the IPCC suggests.

It is also worth noting that the calculations above refer to the difference between 2004 and 1987. In 1987 the WAP JFM AOD was 0.38 which is significantly higher that the estimated WAP JFM AOD in 1950 at 0.09 and the surface forcing of the WAP in 2004 compared to 1950 would be even greater.

Figure 12 shows the M2 JFM surface radiation in 2004 and 1987 and it is obvious that in 2004, the highest WAP Area JFM AOD year, the greatest surface solar radiation in West Africa is now at $15^{\circ}$ to $20^{\circ} \mathrm{N}$ rather than at $0^{\circ}$ to $10^{\circ} \mathrm{N}$ as seen in 1987 and, given that the Hadley Circulation is thermally driven, the entire Hadley Circulation must move north. This can be clearly seen in Figure 10 where the rising limb of the northern Hadley Cell has been altered in the year of high AOD in the WAP Area relative to the low AOD year and the region driving the greatest increase in convection is to the north of the WAP Area. Figure 10 also shows that the falling limb of the northern Hadley Circulation has moved to $35^{\circ}$ to $45^{\circ} \mathrm{N}$ within the SEMIEA latitudes. 


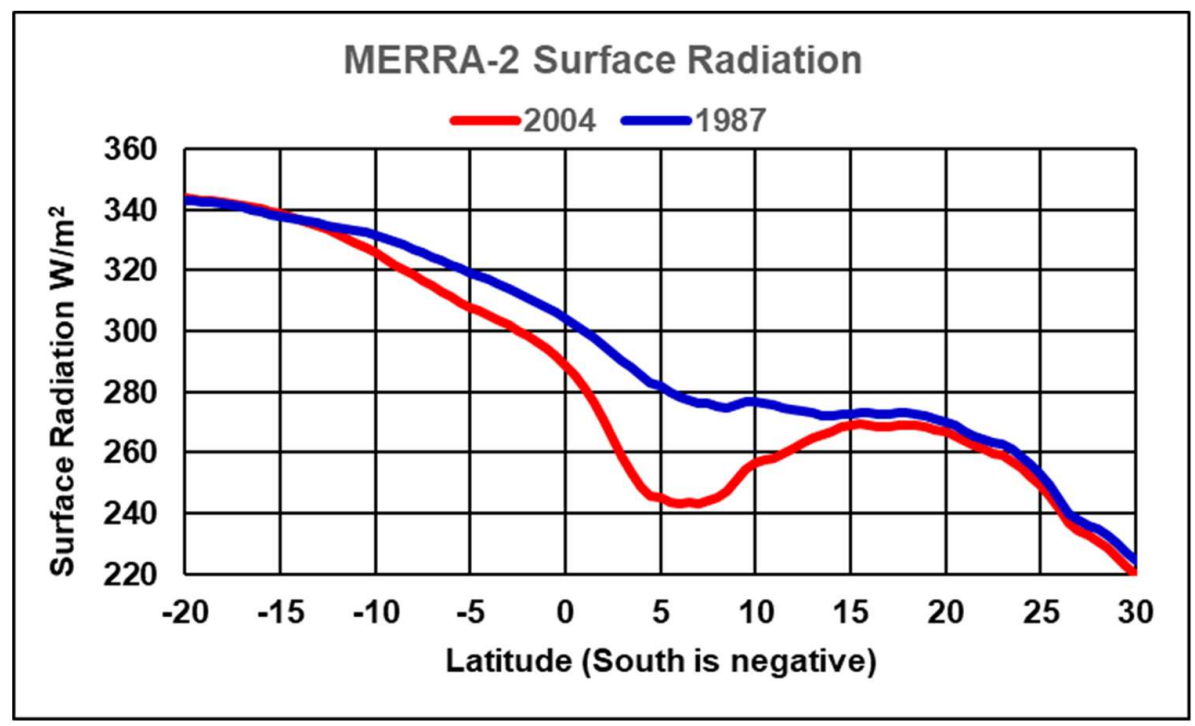

Figure 12. M2 JFM Surface clear sky solar radiation in 1987 and 2004 when WAP Area AOD was 0.38 and 0.9 respectively.

\subsection{Stage 7: The Crucial Step - The WAP Increases Surface Pressure in SEMIEA}

The LME, M2 and TN data in Table 1 (C)(1-2) all show a statistically significant connection between the WAP AOD and PSL in SEMIEA. All datasets at (C)(3-5) and Figure 13(a) show increases in PSL as the WAP AOD level increases and it is worth noting that: the TN data shows a higher trend than the LME in Figure 13(a); and Figure 14 shows a 3 to $5 \mathrm{hPa}$ increase in PSL between 1987 and 2004 in the M2 data which is similar to the trend shown in [20].

It is also worth noting that the estimated LME and TN change from 1950 to the post 2000 average high AOD in Table 1 (C)(5) is greater than the changes shown in Figure 7 in [20] from 1950 to 2007 which the modelling cited in the paper does not replicate.

The eight individual LME simulations in Table 2 and Figure 13(b) show an average increase in the SEMIEA PSL of $13.12 \mathrm{hPa}$ per unit AOD increase and an average correlation of 0.75 (significance $<0.01$ ).

Figure 10 shows the vertical profile of omega from $20^{\circ} \mathrm{S}$ to $70^{\circ} \mathrm{N}$ averaged across the WAP Area longitudes and it is clear that a major change in omega occurs between $35^{\circ} \mathrm{N}$ and $45^{\circ} \mathrm{N}$ where an increase in omega in the high WAP AOD years leads to the higher pressure over the SEMIEA. 


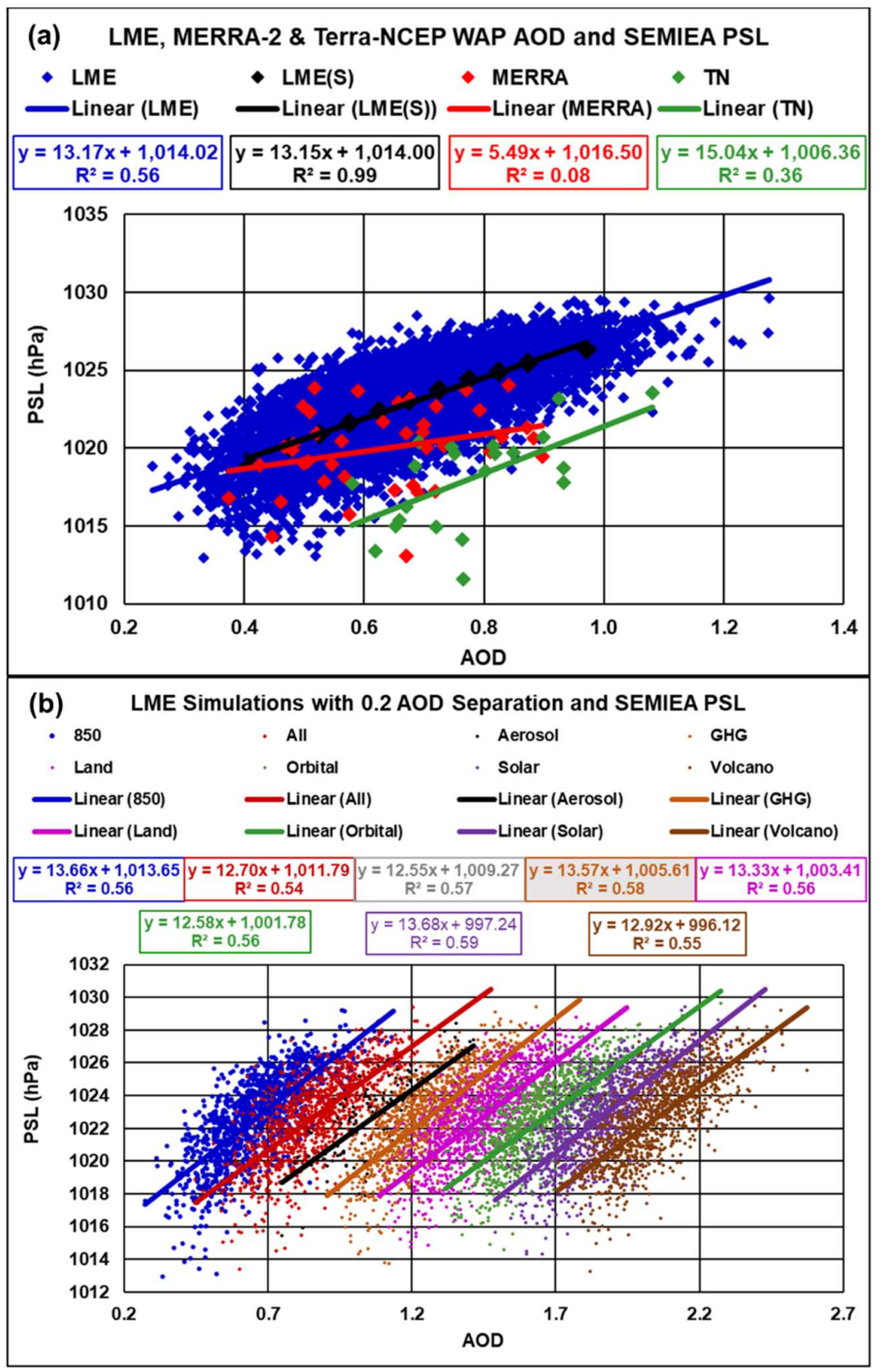

Figure 13. JFM WAP Area AOD and SEMIEA Surface Pressure. (a) LME, M2 and TN and (b) the eight Individual LME Simulations separated by adding 0.0, 0.2, 0.4, 0.6. 0.8. 1.0, 1.2 and 1.4 to the AOD. 


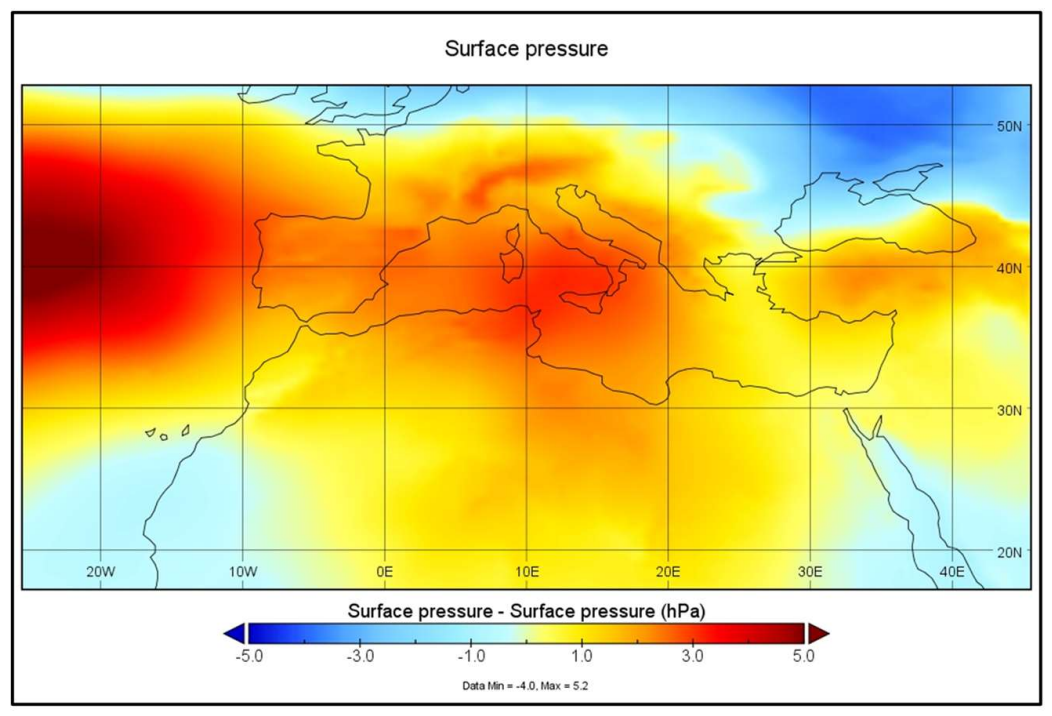

Figure 14. M2 JFM Surface Pressure 2004 minus 1987

Note: This is the crucial step in the changes forced by the WAP and it is the only change remote from West Africa directly controlled by the WAP by the perturbation of the Hadley Circulation with all other changes, flooding in the UK, drought in Iberia and higher winter temperatures in northern Europe being secondary effects which are driven by this anomalous and persistent region of increased surface pressure as the literature states.

\subsection{Stage 8: The WAP Reduces Precipitation in the MIEA}

The LME, M2 and TN data in Table 1 (D)(1-2) all show a statistically significant connection between the WAP AOD and PRECL in the MIEA. All datasets at (D)(3-5) and Figure 15(a) show reductions in PRECL as the WAP AOD level increases and it is worth noting that: the TN data shows a larger negative trend per unit AOD change than the LME in Table 1 and that the average percentage reduction in rainfall across the three datasets in Table 1(D)(6) is $75 \%$ which is similar to the reduction of $60 \%$ in the southern part of Iberia noted in [22]. Figure 16 shows a reduction in JFM PRECL between 1987 and 2004 in the M2 data of up to $60 \mathrm{~mm}$.

The eight individual LME simulations in Table 2 and Figure 15(b) show an average reduction in the MIEA PRECL of $187 \mathrm{~mm}$ per unit AOD increase and an average correlation of -0.64 (significance $<0.01$ ). 


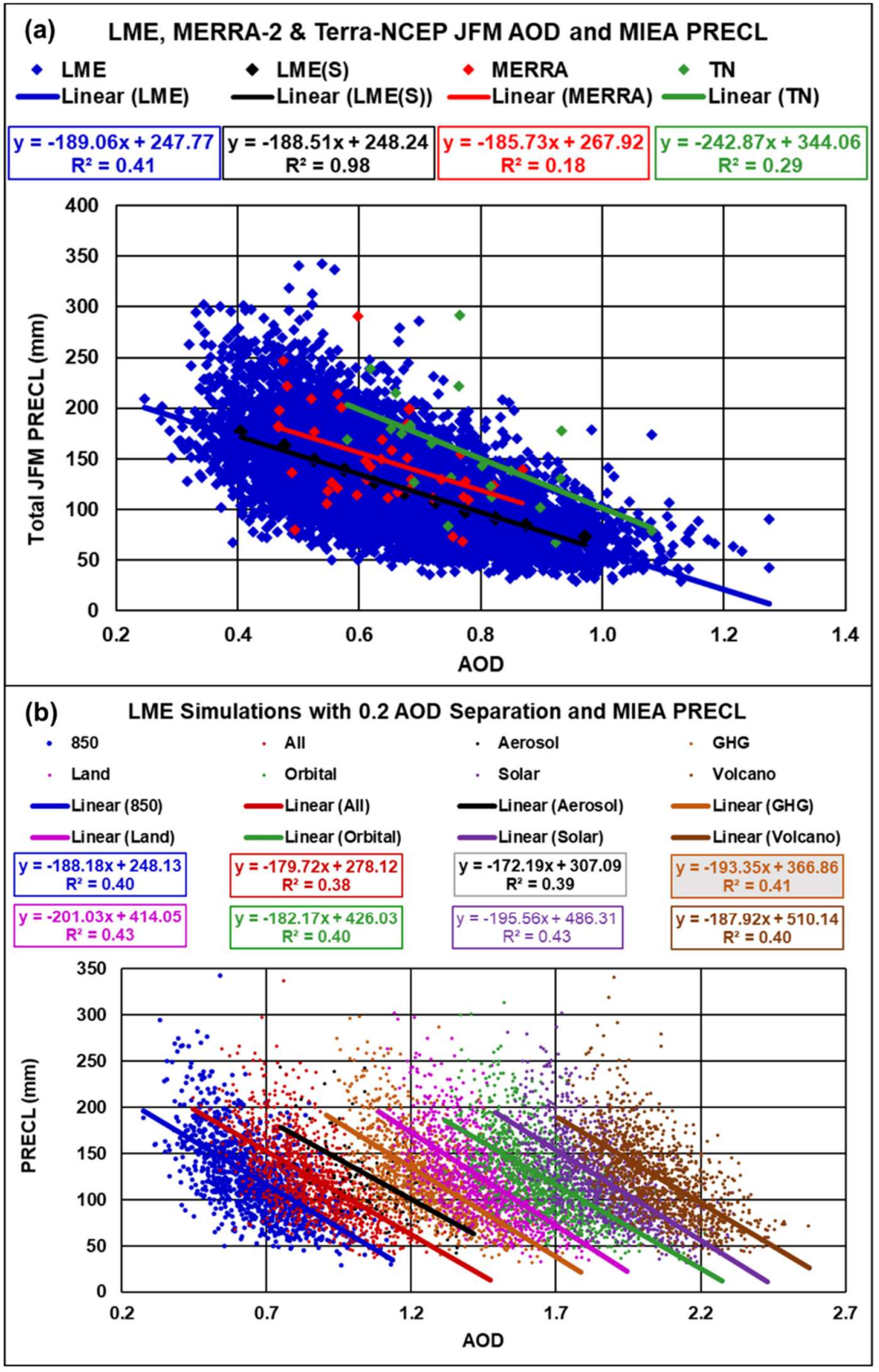

Figure 15. JFM WAP Area AOD and MIEA Precipitation. (a) LME, M2 and TN and (b) the eight Individual LME Simulations separated by adding 0.0, 0.2, 0.4, 0.6. 0.8. 1.0, 1.2 and 1.4 to the AOD. 


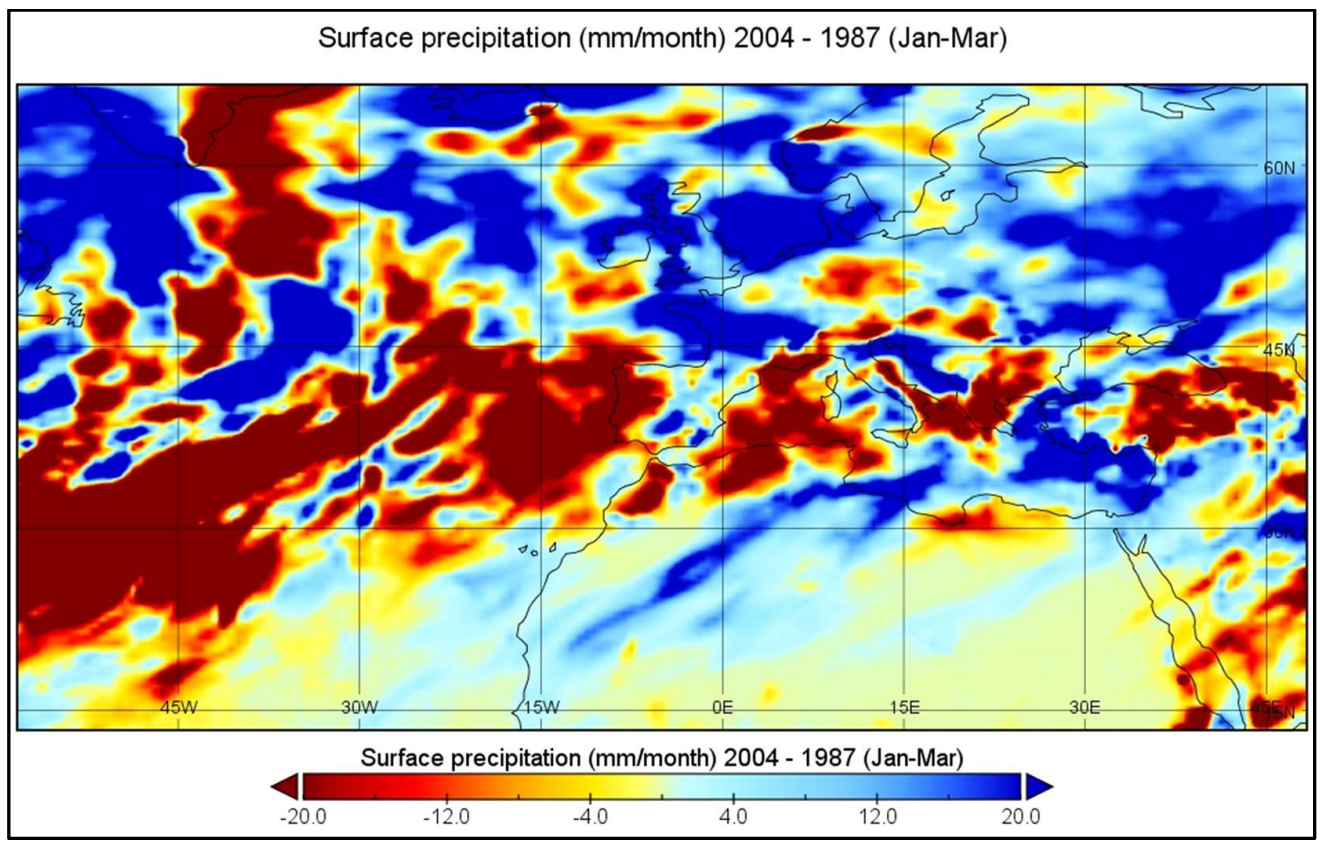

Figure 16. M2 JFM Precipitation in mm/month 2004 minus 1987

\subsection{Stage 9: The WAP Advects Warm, Moist Air into Northern Europe}

With high pressure established over SEMIEA, as Figure 14 shows the natural surface wind flows are significantly perturbed and Figure 17 shows a strong flow from the Atlantic Ocean east of the USA north east across the Atlantic and into the UK and northern Europe. This constitutes an atmospheric river carrying significant moisture from the warm ocean to the UK [27]. Also see: [38] for an early overview of atmospheric rivers; [39] and [40].

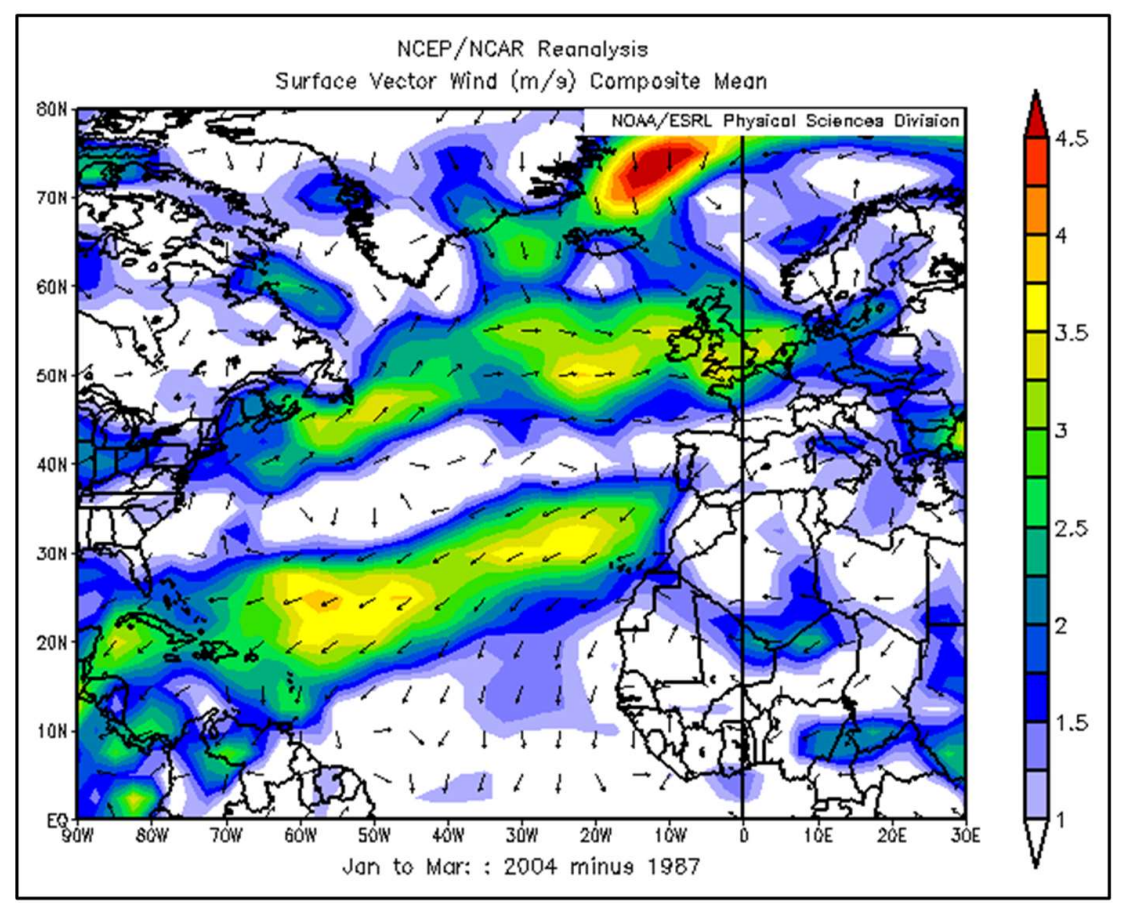

Figure 17. NCEP JFM Surface Vector Wind 2004 minus 1987 


\subsection{Stage 10: The WAP Increases Precipitation in the UK}

The LME and TN data in Table 1 (E)(1-2) show statistically significant connections between the WAP AOD and PRECL in the UK. All datasets at (D)(3-5) and Figure 18(a) show increasing UK PRECL as the WAP AOD level increases and it is worth noting that the TN data shows the largest percentage increase in Table $1(\mathrm{E})(6)$ across the WAP AOD range, being more than double the LME increase. Figure 16 shows an increase of up to 60 $\mathrm{mm}$ between 1987 and 2004 in the JFM M2 data.

It is worth noting that the average increase of $166 \mathrm{~mm}$ in Table 1 (E)(5) from 1950 to the high AOD is of similar, but higher, magnitude to the change in the JFM rainfall in Dunstaffnage in western Scotland, recorded on the UK Met Office website at https://www.metoffice.gov.uk/pub/data/weather/uk/climate/stationdata/dunstaffnagedata.txt, from $411 \mathrm{~mm}$ (pre 1991) to $515 \mathrm{~mm}$ (post 1990) at $+104 \mathrm{~mm}$.

The eight individual LME simulations in Table 2 and Figure 18(b) show an average increase in the UK PRECL of $231 \mathrm{~mm}$ per unit AOD increase and an average correlation of 0.42 (significance $<0.01$ ).

It is also worth noting that the creation of atmospheric rivers from the subtropical Atlantic to the UK only occurs because low pressure systems moving eastwards across the Atlantic meet the persistent and static SEMIEA high pressure region which causes the isobars to close up and, in some cases, depending on the latitude of the low pressure system, create the narrow SW to NE air flow - an atmospheric river. 


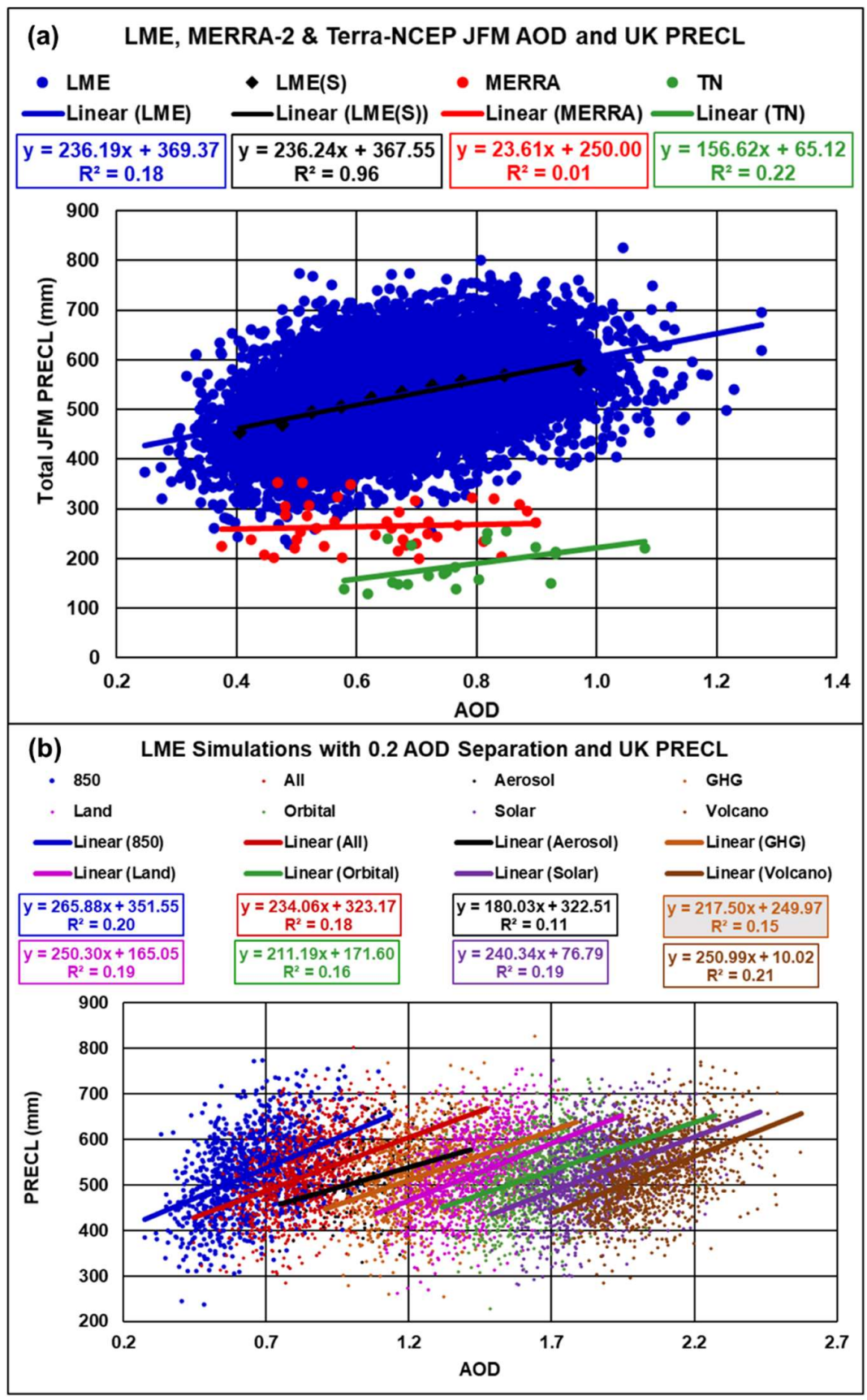

Figure 18: JFM WAP Area AOD and UK Precipitation.(a) LME, M2 and TN and (b) the eight Individual LME Simulations separated by adding $0.0,0.2,0.4,0.6 .0 .8 .1 .0,1.2$ and 1.4 to the AOD.

\subsection{Stage 11: The WAP Increases the Temperature in Northern Europe}

The LME and M2 data in Table 1 (F)(1-2) show statistically significant connections between the WAP AOD and TS in Europe. All datasets at (E)(3-5) and Figure 19(a) show increasing TS as the WAP AOD level increases and it is worth noting that in Table 1 (F)(3) the M2 and TN data shows a larger increase than the LME per unit WAP AOD increase. Figure 20 shows an increase of over $4^{\circ} \mathrm{K}$ across much of Europe north of the Alps between 1987 and 2004 in the M2 data. 
The eight individual LME simulations in Table 2 and Figure 19(b) show an average increase in the temperature $\mathrm{f}$ Europe of $2.44^{\circ} \mathrm{K}$ per unit AOD increase and an average correlation of 0.45 (significance $<0.01$ ).

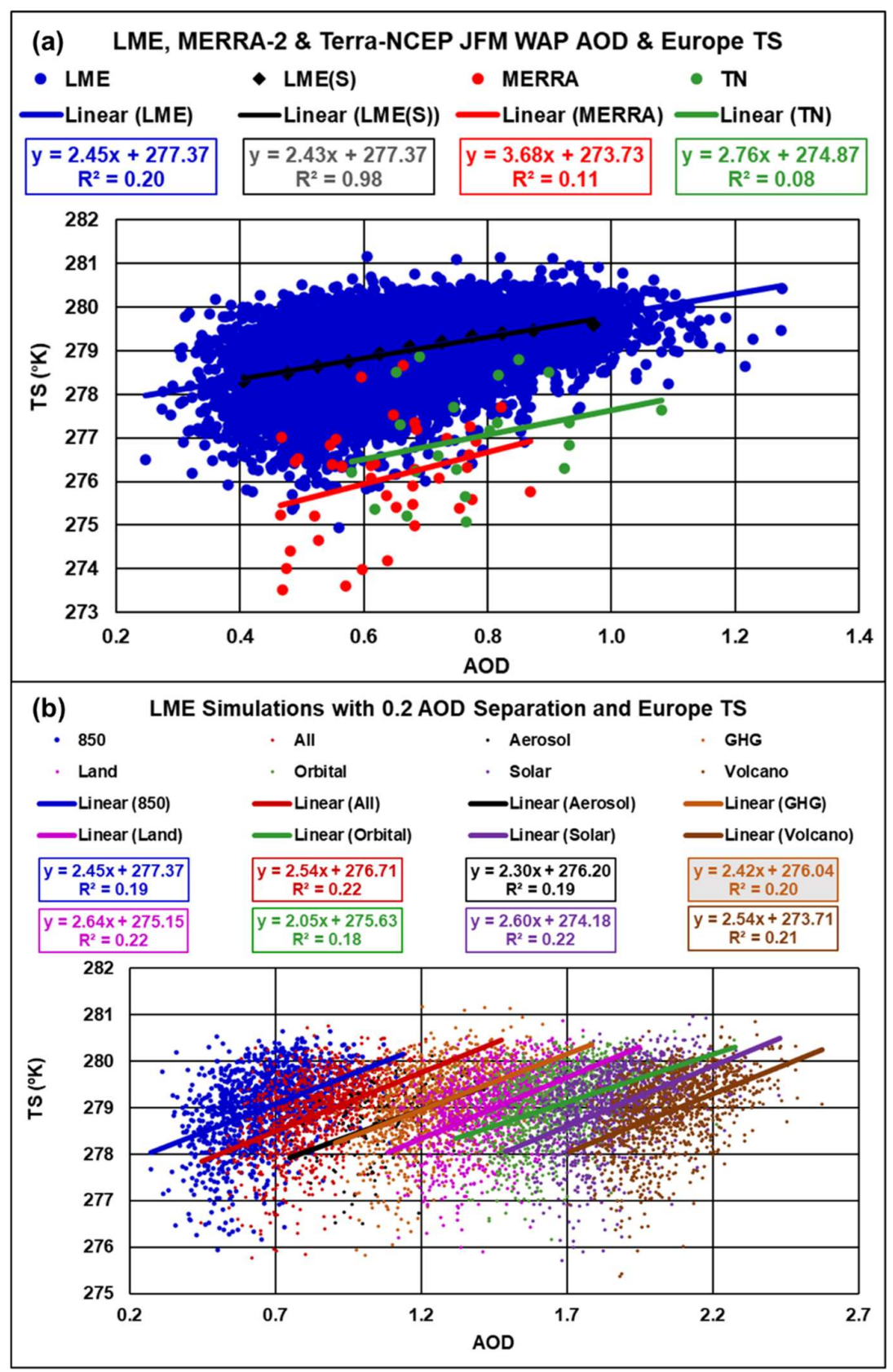

Figure 19. JFM WAP Area AOD and Northern European Temperature. (a) LME, M2 and TN and (b) the eight Individual LME Simulations separated by adding 0.0, 0.2, 0.4, 0.6. 0.8. 1.0, 1.2 and 1.4 to the AOD. 


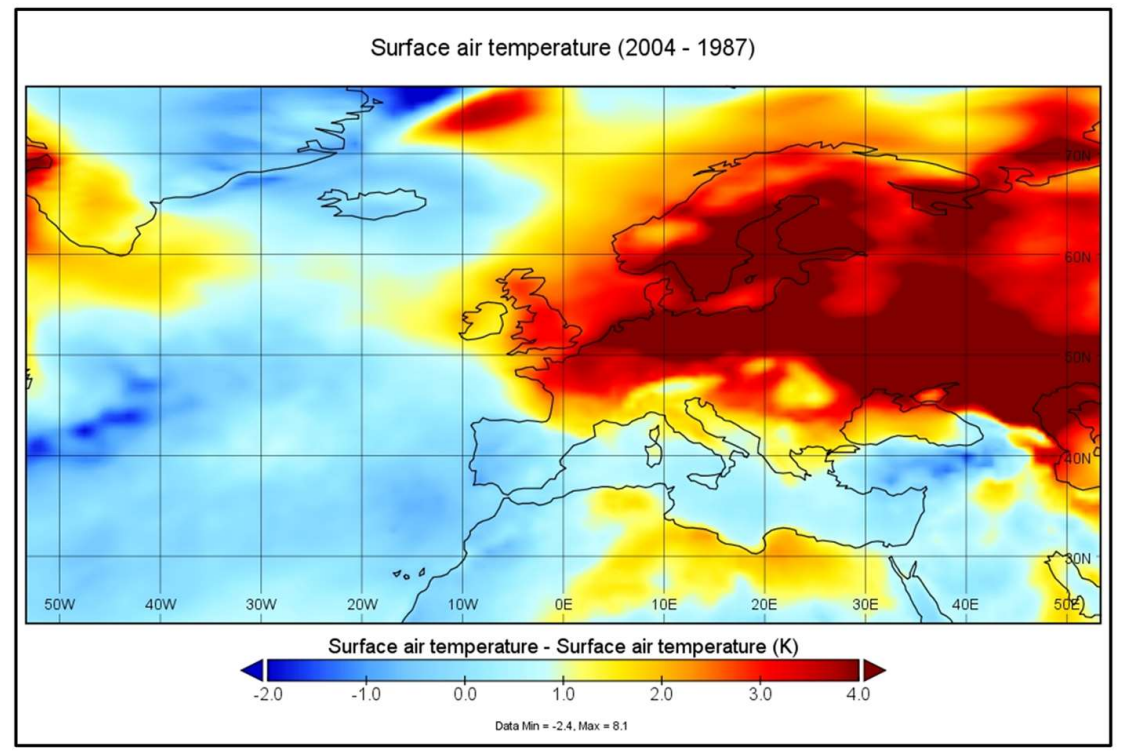

Figure 20. MERRRA-2 JFM Surface Temperature 2004 minus 1987

\section{CAUSATION ANALYSIS}

It is clearly understood that correlation between events A and B does not prove causation from A to B or vice versa. Thus, the causal relationship between the WAP and the European climate must be demonstrated in other ways.

\subsection{Multiple Datasets}

This paper analyses three independent datasets: the LME, with 1,156 years of data and eight different forcing scenarios; the M2 reanalysis with 41 years of data including assimilated aerosol measurements; and TN with 21 years of measured aerosol data. All datasets show the same trends in the parameters analysed and 14 out of the 18 analyses show statistically significant correlations.

The eight LME individual simulations show little variation between the simulations indicating that the forcing agents simulated have little influence on the parameters analysed compared to the WAP Area AOD.

\subsection{Analysis without Correlation}

This section shows that this paper provides results which reflect actual measurements.

\subsubsection{Pressure over the SEMIEA}

When the "all simulation" LME PSL data from years when WAP AOD is below 0.45 and above 0.90 is averaged, the PSL change from low AOD to high is $7.2 \mathrm{hPa}$ which mirrors the trend shown in [20], whereas the modelling in that paper which does not include the carbonaceous WAP, does not. The TN data shows an even higher positive trend in PSL than the LME data whilst the M2 data shows a lower but still significant positive trend.

\subsubsection{Precipitation in Iberia}

When the "all simulation" LME PRECL data from years when WAP AOD is below 0.45 and above 0.90 is averaged, the change from low AOD to high is $-103 \mathrm{~mm}$ or $-59 \%$, which nearly exactly matches the measured Iberian rainfall reduction in the 2004/05 water year of $60 \%$ [22]. The average of all three datasets in Table 1(D)(6) shows a similar reduction from the estimated WAP AOD in 1950 to the high at $47 \%$.

\subsubsection{Precipitation in The U.K.}


When the "all simulation" LME PRECL data from years when WAP AOD is below 0.45 and above 0.90 is averaged, the change from low AOD to high is $127 \mathrm{~mm}$ or $28 \%$, which is the same order of magnitude as the change in the recorded UK (ex Northern Ireland) rainfall (UK Met Office at https://www.metoffice.gov.uk/research/climate/mapsand-data/uk-and-regional-series) from the average from 1862 to 1988, to the average from 1989 to 2020 at $17 \%$.

\subsubsection{Warmer Temperatures in Europe.}

Using the trend in the "all simulation" LME TS data, 2.45 $\mathrm{K}$ per unit AOD increase, the TS change from the estimated low AOD of 0.09 in 1950 to the measured high in the Terra AOD data in Figure 2, 1.2 in Feb /March 2000, is 2.72 ${ }^{\circ} \mathrm{K}$ which mirrors the trend described in [20] whereas the modelling in that paper, which does not include the carbonaceous WAP, does not. It is also worth noting that the CRUTEM.4.6.0.0 land temperature data [41] from the same region shows a trend increase of $2.90^{\circ} \mathrm{K}$ from 1950 to 2007 which is obviously similar to the results from all three datasets.

\subsection{Modelling}

LME: there is no physical mechanism by which drought or SLP in SEMIEA can create aerosols in the LME over West Africa, hence the causal direction must run from the aerosols to the rainfall and SLP.

In addition, the aerosol forcings in all LME runs are fixed at 1850 values except for the "ozone and aerosol" and "all" runs and there can therefore be no forcing of the aerosols by any agent within these six runs and the causal direction must flow from the aerosols to the rainfall and SLP.

The similarity of the LME individual simulations clearly shows that forcing agents within each simulation have little effect on the parameters analysed compared to the WAP Area AOD.

M2: this reanalysis assimilates measured aerosol data and therefore the causal direction must be from the aerosols to the rainfall and SLP as it cannot be the reverse.

TN: this dataset includes measured aerosol data, and as stated above and in Appendix B, the source of the WAP aerosols is undoubtedly anthropogenic.

\subsection{Multiple Independent Datasets in the LME}

The eight LME modelling runs exhibit very low or negative correlations between the WAP AOD in the individual runs as shown in the correlation matrix in Appendix F with an overall average 0.0016 . Hence the datasets are independent.

All the eight LME datasets show correlations at magnitude -0.62 and 0.74 or greater with the Iberian rainfall and SEMIEA SLP respectively at significance of $<0.01$ or less and the chance that all these eight independent datasets show the same result and are wrong is the product of the significance i.e., $0.01^{8}$ or $10^{-16}$, a vanishingly small number.

\subsection{Another Event " $\mathrm{C}$ "}

One possible explanation for the correlations shown in this paper is that another unknown event "C" causes the WAP and all the other effects discussed in this paper simultaneously.

However, Appendix B shows the JFM WAP is unquestionably anthropogenic and caused by biomass burning in deliberately lit fires and gas flares in West Africa and it is therefore impossible for another event to cause the WAP and the changes in Europe discussed here and this possibility must be rejected.

\subsection{Causal Direction}

Therefore with:

1. All the datasets showing, without using correlation:

a. An increase in pressure in the SEMIEA as the AOD level of the WAP rises;

b. An increase in rainfall in the UK as the AOD level of the WAP rises;

c. A reduction in rainfall in Iberia as the AOD level of the WAP rises; 
d. An increase in temperature in northern Europe as the AOD level of the WAP rises.

2. The detrended LME time series analysis showing the same results across multiple independent datasets forced by different agents including variations in: greenhouse gases; land use; orbit; the sun; and volcanic eruptions with a vanishingly small chance of error;

the inevitable conclusion is that the hypothesis is proven and the WAP is the primary driver in JFM of increased pressure over the SEMIEA and a significant driver of increased rainfall in the UK and temperature in northern Europe and reduced rainfall in Iberia.

\section{FUTURE RESEARCH}

\subsection{Confirming the conclusions}

To finally confirm the findings above, I suggest that a further LME style analysis is undertaken in which an aerosol plume is created in the model over West Africa, which ramps up from the naturally low level which existed in 1950 in November to reach the same AOD and geographic extent as the extreme JFM WAP of 2004 in January, continues at the same level to March and ramps down in April to the naturally low level which existed in May 1950. This plume to be applied in the model with random returns from 3 to 10 years to mimic the return frequency of high AOD events in Figures 2 and 3 with all other forcing agents held constant.

This modelling should be repeated with AOD levels reduced by perhaps $25 \%$ between runs to determine the level of AOD in the WAP Area which is required to create the effects demonstrated in this paper.

These experiments will confirm the analysis in this paper and provide the information governments will require to undertake the actions needed to reduce the WAP AOD to levels which will not impact the winter climate of Europe and will allow it to return to its natural state without the anthropogenic influence of the WAP.

\subsection{Mitigating the WAP}

\subsubsection{Seasonal Biomass Burning}

The most significant source of aerosols in the extreme WAP is biomass burning which takes place towards the end of the dry season in West Africa in JFM. The biomass is burned for the reasons outlined in Appendix B.

Reducing the incidence of biomass burning requires the deployment of new technologies which are now available to take the unwanted biomass and convert it into useful products such as liquid fuel which, of course, would be carbon dioxide neutral as the feedstock is not a fossil fuel. MIT in 2015 produced a report into this technology: Biomass to Liquid Fuels Pathways [42] and there are many others such as [43].

Deployment of this technology might enable the rapid reduction of the AOD levels over West Africa as the technology would create a new income stream for farmers and others selling into a new industry, and it would enable West African governments to ban biomass burning in the open as other governments have done.

\subsubsection{Gas Flares}

The anthropogenic WAP also comprises carbonaceous aerosols from the routine flaring of associated gas in the oil production industry. (Associated gas is gas dissolved in liquid oil which boils out of the liquid when the oil is produced from deep in the Earth (typically 1,500 to 3,000 metres depth) and the pressure reduces to atmospheric levels. Associated gas produced in areas without infrastructure to use the gas is flared. A process which is, indubitably, wasteful.)

The World Bank via the Global Gas Flaring Reduction Partnership (GGFRP) has been trying to reduce routine flaring in the oil industry with some success in West Africa with the amount of gas flared in Nigeria reducing from 8.4 to 7.4 billion cubic metres $(\mathrm{bcm})$ per annum between 2014 and 2018 according the GGFRP website at https://www.worldbank.org/en/programs/gasflaringreduction\#7 . 
Even with this success, the oil industry still flares a significant amount of gas in Nigeria which, in 2018, was the $7^{\text {th }}$ largest flaring country in the World and the industry should be required to immediately eliminate the routine flaring of gas by government or, at a minimum, to flare the gas without creating aerosols until routine flaring can be eliminated.

\subsubsection{Background AOD Levels}

The background AOD level refers to the average level between May and November, a period when extreme biomass burning cannot occur due to the West African monsoon.

The representative concentration pathway data from the International Institute for Applied Systems Analysis (IIASA) at https://www.iiasa.ac.at/web/home/research/researchPrograms/TransitionstoNewTechnologies/RCP.en.html shows no change in carbonaceous aerosols from the MAF area (Middle East and Africa) before 1950 and then a sixfold increase by 2000 with the majority of the increase occurring by 1970 . Hence as West Africa is one of the regions where there has been a significant increase, it is obvious that the WAP Area background AOD level in 1950 must have been significantly lower than the 1980 level shown in Figure 3. It is therefore possible that this increased background level since 1950 may have also affected the climate of Europe in other seasons and this requires further research.

\subsubsection{Other Aerosol Plumes}

Eight continental scale aerosol plumes (Appendix A) now exist in the World each year, each in its own season and they all will have significant effects on atmospheric circulation and therefore the local, regional and possibly global climates.

\section{CONCLUSIONS}

The LME with 1.156 years of data and eight different forcing simulations, M2 with 40 years of data and TN with 21 years of data confirm the direct connection between the WAP and the European winter climate in multiple independent ways. The individual LME simulations clearly show there is little, if any, difference between the simulations using different forcing agents and confirm that the prime agent forcing the winter climate of Europe is, in fact, the AOD of the West African Aerosol Plume. All the data and my analysis clearly shows that the relationship between the WAP AOD and the changed climate of Europe must be causal.

I therefore conclude that:

1. The hypothesis is proven and that Aerosol Regional Dimming by apparitions of the WAP is the prime trigger for, and sustaining influence on, changes in the winter climate of Europe driving increased pressure over SEMIEA which then creates increased rainfall in the UK, drought in Iberia and increased temperatures in northern Europe.

2. The reason that the climate modelling cited in the introduction failed to replicate the significant observed surface pressure rise over the Mediterranean is, of course, that the models did not accurately incorporate the carbonaceous, anthropogenic aerosols of the WAP.

3. The WAP and the other seven continental scale aerosol plumes which now exist each year, each in its own season, must be accurately incorporated in climate models at spatial and temporal resolutions that do not lose the effects of the plumes due to averaging. I suggest a spatial resolution of less than $2^{\circ}$ of latitude and longitude and a temporal resolution of less than 1 month are required to do this.

4. With the proof that the WAP changes the climate of Europe 40 to 50 degrees of latitude away, it is obviously possible that the other seven continental scale aerosol plumes may have effects which are even more remote from the plume than the WAP is from Europe and this requires investigation.

Finally, I concur with [44] that emissions of carbonaceous aerosols are directly addressable by government policy actions and suggest that this is an urgent necessity to restore the winter climate of Europe to its pre-WAP, natural state circa 1950. 


\section{SUPPORTING INFORMATION}

The following Supporting Information is provided:

Appendix A The Eight Continental Scale Aerosol Plumes

Appendix B The Sources of the West African Aerosol Plume

Appendix C Aerosols and Climate

Appendix D Data Sources

Appendix E LME and MERRA-2 Model and Terra Data Information

Appendix F Correlation Matrix for LME and M2

\section{ACKNOWLEDGEMENTS}

I acknowledge:

NASA: Analyses and visualizations used in this paper were produced with the Giovanni online data system, developed and maintained by the NASA GES DISC; the mission scientists and Principal Investigators who provided the data and images used in this paper including the M2 data; and Dr Robert Schmunk for the Panoply data viewer;

NASA for the fire data at https://earthdata.nasa.gov/earth-observation-data/nearreal-time/firms/active-fire-data ;

NASA for the CALIPSO data obtained from the NASA Langley Research Center Atmospheric Science Data Center at https://eosweb.larc.nasa.gov/project/calipso/calipso table.

The NOAA/ESRL Physical Sciences Division, Boulder Colorado for the data and images from their Web site at http://www.esrl.noaa.gov/psd/.

The CESM1(CAM5) Last Millennium Ensemble Community Project and supercomputing resources provided by NSF/CISL/Yellowstone;

The UK Met Office at https://www.metoffice.gov.uk/weather/learn-about/past-ukweather-events for the UK flood information, rainfall and temperature data;

The IPCC for the images from Assessment Report Four;

Google Earth ${ }^{\mathrm{TM}}$ and the copyright holders noted on the image for the image of the Earth;

The United Nations Department of Economic and Social Affairs Population Division for the world population statistics at https://www.un.org/en/development/desa/population/publications/database/index.asp; data;

The Global Forest Watch at https://www.globalforestwatch.org/for the forest loss

BP for the oil production statistics at https://www.bp.com/en/global/corporate/energy-economics/statistical-review-of-world-energy.html

The Global Gas Flaring Reduction Partnership (World Bank and NOAA) for the gas flare data and image of a flare at https://www.worldbank.org/en/programs/gasflaringreduction;

The Global Volcanism Program at the Smithsonian Institution for the volcano eruption data. http://dx.doi.org/10.5479/si.GVP.VOTW4-2013 ;

All data supporting the conclusions is available from the sources noted in the text.

Conflicts of Interest: The authors declare no conflict of interest. 


\section{References}

1. Remer, L.A.; Kaufman, Y.J.; Tanré, D.; Mattoo, S.; Chu, D.A.; Martins, J.V.; Li, R.R.; Ichoku, C.; Levy, R.C.; Kleidman, R.G.; et al. The MODIS Aerosol Algorithm, Products, and Validation. Journal of the Atmospheric Sciences 2005, 62, 947-973, doi:10.1175/JAS3385.1.

2. Kaufman, Y.J.; Holben, B.N.; Tanré, D.; Slutsker, I.; Smirnov, A.; Eck, T.F. Will aerosol measurements from Terra and Aqua Polar Orbiting satellites represent the daily aerosol abundance and properties? Geophysical Research Letters 2000, 27, 38613864, doi:10.1029/2000GL011968.

3. Otto-Bliesner, B.L.; Brady, E.C.; Fasullo, J.; Jahn, A.; Landrum, L.; Stevenson, S.; Rosenbloom, N.; Mai, A.; Strand, G. Climate Variability and Change since $850 \mathrm{CE}$ : An Ensemble Approach with the Community Earth System Model. Bulletin of the American Meteorological Society 2016, 97, 735-754, doi:10.1175/bams-d-14-00233.1.

4. Gelaro, R.; McCarty, W.; Suárez, M.J.; Todling, R.; Molod, A.; Takacs, L.; Randles, C.A.; Darmenov, A.; Bosilovich, M.G.; Reichle, R.; et al. The Modern-Era Retrospective Analysis for Research and Applications, Version 2 (MERRA-2). Journal of Climate 2017, 30, 5419-5454, doi:10.1175/jcli-d-16-0758.1.

5. Kalnay, E.; Kanamitsu, M.; Kistler, R.; Collins, W.; Deaven, D.; Gandin, L.; Iredell, M.; Saha, S.; White, G.; Woollen, J.; et al. The NCEP/NCAR 40-Year Reanalysis Project. Bulletin of the American Meteorological Society 1996, 77, 437-471, doi:10.1175/1520-0477(1996)077<0437:TNYRP>2.0.CO;2.

6. $\quad$ Remer, L.; RC, L.; S, M.; D, T.; P, G.; Y, S.; V, S.; LA, M.; Y, Z.; M, K.; et al. The Dark Target Algorithm for Observing the Global Aerosol System: Past, Present, and Future. Remote Sensing of Environment 2020, 12, doi:10.3390/rs12182900.

7. Oluleye, A.; Ogunjobi, K.O.; Bernard, A.; Ajayi, V.O.; A.A., A. Multiyear Analysis of Ground-Based Sunphotometer (AERONET) Aerosol Optical Properties and its Comparison with Satellite Observations over West Africa. Global Journal of HUMAN SOCIAL SCIENCE Geography E Environmental GeoSciences 2012, 12.

8. Fawole, O.G.; Cai, X.M.; MacKenzie, A.R. Gas flaring and resultant air pollution: A review focusing on black carbon. Environmental Pollution 2016, 216, 182-197, doi:https://doi.org/10.1016/j.envpol.2016.05.075.

9. Dey, S.; Tripathi, S.N. Estimation of aerosol optical properties and radiative effects in the Ganga basin, northern India, during the wintertime. Journal of Geophysical Research: Atmospheres 2007, 112, doi:https://doi.org/10.1029/2006JD007267.

10. Dey, S.; Tripathi, S.N. Aerosol direct radiative effects over Kanpur in the Indo-Gangetic basin, northern India: Long-term (2001-2005) observations and implications to regional climate. Journal of Geophysical Research: Atmospheres 2008, 113, doi:https://doi.org/10.1029/2007JD009029.

11. Guleria, R.P.; Kuniyal, J.C.; Rawat, P.S.; Sharma, N.L.; Thakur, H.K.; Dhyani, P.P.; Singh, M. The assessment of aerosol optical properties over Mohal in the northwestern Indian Himalayas using satellite and ground-based measurements and an influence of aerosol transport on aerosol radiative forcing. Meteorology and Atmospheric Physics 2011, 113, 153, doi:10.1007/s00703-011-0149-5.

12. Guleria, R.P.; Kuniyal, J.C.; Dhyani, P.P.; Joshi, R.; Sharma, N.L. Impact of aerosol on surface reaching solar irradiance over Mohal in the northwestern Himalaya, India. Journal of Atmospheric and Solar-Terrestrial Physics 2014, 108, 41-49, doi:https://doi.org/10.1016/j.jastp.2013.12.002.

13. Babu, S.S.; Manoj, M.R.; Moorthy, K.K.; Gogoi, M.M.; Nair, V.S.; Kompalli, S.K.; Satheesh, S.K.; Niranjan, K.; Ramagopal, K.; Bhuyan, P.K.; et al. Trends in aerosol optical depth over Indian region: Potential causes and impact indicators. Journal of Geophysical Research: Atmospheres 2013, 118, 2013JD020507, doi:10.1002/2013JD020507.

14. Rajeev, K.; Parameswaran, K.; Nair, S.K.; Meenu, S. Observational evidence for the radiative impact of Indonesian smoke in modulating the sea surface temperature of the equatorial Indian Ocean. Journal of Geophysical Research: Atmospheres 2008, 113, doi:https://doi.org/10.1029/2007JD009611.

15. Ramanathan, V. ATMOSPHERIC BROWN CLOUDS: HEALTH, CLIMATE AND AGRICULTURE IMPACTS. Scripta Varia 2006, 106. 
16. Duncan, B.N.; Bey, I.; Chin, M.; Mickley, L.J.; Fairlie, T.D.; Martin, R.V.; Matsueda, H. Indonesian wildfires of 1997: Impact on tropospheric chemistry. Journal of Geophysical Research: Atmospheres 2003, 108, 4458, doi:10.1029/2002JD003195.

17. Hansell, R.A.; Tsay, S.C.; Ji, Q.; Liou, K.N.; Ou, S.C. Surface aerosol radiative forcing derived from collocated ground-based radiometric observations during PRIDE, SAFARI, and ACE-Asia. Appl Opt 2003, 42, 5533-5544.

18. Fan, J.; Zhang, R.; Tao, W.-K.; Mohr, K.I. Effects of aerosol optical properties on deep convective clouds and radiative forcing. Journal of Geophysical Research: Atmospheres 2008, 113, doi:https://doi.org/10.1029/2007JD009257.

19. Hodzic, A.; Duvel, J.P. Impact of Biomass Burning Aerosols on the Diurnal Cycle of Convective Clouds and Precipitation Over a Tropical Island. Journal of Geophysical Research: Atmospheres 2018, 123, 1017-1036, doi:https://doi.org/10.1002/2017JD027521.

20. van Oldenborgh, G.J.; Drijfhout, S.; van Ulden, A.; Haarsma1, R.; Sterl, A.; Severijns, C.; Hazeleger, W.; Dijkstra, H. Western Europe is warming much faster than expected. Climate of the Past 2009, 5, 1 - 12.

21. Sterl, A.; Severijns, C.; Dijkstra, H.; Hazeleger, W.; Jan van Oldenborgh, G.; van den Broeke, M.; Burgers, G.; van den Hurk, B.; Jan van Leeuwen, P.; van Velthoven, P. When can we expect extremely high surface temperatures? Geophysical Research Letters 2008, 35, doi:10.1029/2008g1034071.

22. García-Herrera, R.; Paredes, D.; Trigo, R.M.; Trigo, I.F.; Hernández, E.; Barriopedro, D.; Mendes, M.A. The Outstanding 2004/05 Drought in the Iberian Peninsula: Associated Atmospheric Circulation. Journal of Hydrometeorology 2007, 8, 483-498, doi:10.1175/jhm578.1.

23. Vicente-Serrano, S.M.; López-Moreno, J.I. The influence of atmospheric circulation at different spatial scales on winter drought variability through a semi-arid climatic gradient in Northeast Spain. International Journal of Climatology 2006, 26, 1427-1453, doi:10.1002/joc.1387.

24. Chiverrell, R.C.; Sear, D.A.; Warburton, J.; Macdonald, N.; Schillereff, D.N.; Dearing, J.A.; Croudace, I.W.; Brown, J.; Bradley, J. Using lake sediment archives to improve understanding of flood magnitude and frequency: Recent extreme flooding in northwest UK. Earth Surface Processes and Landforms 2019, 44, 2366-2376, doi:10.1002/esp.4650.

25. Huntingford, C.; Marsh, T.; Scaife, A.A.; Kendon, E.J.; Hannaford, J.; Kay, A.L.; Lockwood, M.; Prudhomme, C.; Reynard, N.S.; Parry, S.; et al. Potential influences on the United Kingdom's floods of winter 2013/14. Nature Clim. Change 2014, 4, 769777, doi:10.1038/nclimate2314.

26. Schaller, N.; Kay, A.L.; Lamb, R.; Massey, N.R.; van Oldenborgh, G.J.; Otto, F.E.L.; Sparrow, S.N.; Vautard, R.; Yiou, P.; Ashpole, I.; et al. Human influence on climate in the 2014 southern England winter floods and their impacts. Nature Clim. Change 2016, 6, 627-634, doi:10.1038/nclimate2927.

27. Lavers, D.A.; Allan, R.P.; Wood, E.F.; Villarini, G.; Brayshaw, D.J.; Wade, A.J. Winter floods in Britain are connected to atmospheric rivers. Geophysical Research Letters 2011, 38, doi:10.1029/2011g1049783.

28. Yiou, P.; Vautard, R.; Naveau, P.; Cassou, C. Inconsistency between atmospheric dynamics and temperatures during the exceptional 2006/2007 fall/winter and recent warming in Europe. Geophysical Research Letters 2007, 34, doi:10.1029/2007g1031981.

29. Cattiaux, J.; Vautard, R.; Cassou, C.; Yiou, P.; Masson-Delmotte, V.; Codron, F. Winter 2010 in Europe: A cold extreme in a warming climate. Geophysical Research Letters 2010, 37, doi:10.1029/2010g1044613.

30. Luterbacher, J.; Liniger, M.A.; Menzel, A.; Estrella, N.; Della-Marta, P.M.; Pfister, C.; Rutishauser, T.; Xoplaki, E. Exceptional European warmth of autumn 2006 and winter 2007: Historical context, the underlying dynamics, and its phenological impacts. Geophysical Research Letters 2007, 34, doi:10.1029/2007gl029951.

31. Osborn, T.J. Simulating the winter North Atlantic Oscillation: the roles of internal variability and greenhouse gas forcing. Climate Dynamics 2004, 22, doi:10.1007/s00382-004-0405-1.

32. Osborne, J.M.; Lambert, F.H. The missing aerosol response in twentieth-century mid-latitude precipitation observations. Nature Clim. Change 2014, 4, 374-378, doi:10.1038/nclimate2173 
http://www.nature.com/nclimate/journal/v4/n5/abs/nclimate2173.html\#supplementary-information.

33. Hammer, Ø.; Harper, D.A.T.; Ryan, P.D. PAST: Paleontological statistics software package for education and data analysis. . Palaeontologia Electronica 4(1): 9pp 2001, 9pp.

34. Winker, D.M.; Vaughan, M.A.; Omar, A.; Hu, Y.; Powell, K.A.; Liu, Z.; Hunt, W.H.; Young, S.A. Overview of the CALIPSO Mission and CALIOP Data Processing Algorithms. Journal of Atmospheric and Oceanic Technology 2009, 26, 2310-2323, doi:10.1175/2009jtecha1281.1.

35. McGregor, G.R.; Nieuwolf, S. Tropical Climatology; John Wiley and Sons: 1977; p. 207.

36. Barry, R.G.; Chorley, R.J. Atmosphere Weather and Climate Routledge, Abingdon UK: 2010.

37. IPCC. IPCC Assessment Report 4 Glossary. 2007.

38. Ralph, F.M.; Dettinger, M.D. Storms, floods, and the science of atmospheric rivers. Eos, Transactions American Geophysical Union 2011, 92, 265-266, doi:10.1029/2011eo320001.

39. Lavers, D.A.; Villarini, G. The nexus between atmospheric rivers and extreme precipitation across Europe. Geophysical Research Letters 2013, 40, 3259-3264, doi:10.1002/grl.50636.

40. Young, A.M.; Skelly, K.T.; Cordeira, J.M. High-impact hydrologic events and atmospheric rivers in California: An investigation using the NCEI Storm Events Database. Geophysical Research Letters 2017, 44, 3393-3401, doi:10.1002/2017GL073077.

41. Jones, P.D.; Lister, D.H.; Osborn, T.J.; Harpham, C.; Salmon, M.; Morice, C.P. Hemispheric and large-scale land-surface air temperature variations: An extensive revision and an update to 2010. Journal of Geophysical Research: Atmospheres 2012, 117, doi:10.1029/2011jd017139.

42. Seifkar, N.; Lu, X.; Withers, M.; Malina, R.; Field, R.; Barrett, S.; Herzog, H. Biomass to Liquid Fuels Pathways; 2015.

43. Graham, P.W.; Brinsmead, T.S.; Reedman2, L.J. An assessment of competition for biomass resources within the energy and transport sectors; CSIRO: 2011.

44. Booth, B.B.; Dunstone, N.J.; Halloran, P.R.; Andrews, T.; Bellouin, N. Aerosols implicated as a prime driver of twentiethcentury North Atlantic climate variability. Nature 2012, 484, 228-232, doi:10.1038/nature10946. 